\title{
Differences in ozone retrieval in MIPAS channels A and AB: a spectroscopic issue
}

\author{
Norbert Glatthor ${ }^{1}$, Thomas von Clarmann ${ }^{1}$, Gabriele P. Stiller ${ }^{1}$, Michael Kiefer ${ }^{1}$, Alexandra Laeng ${ }^{1}$, \\ Bianca M. Dinelli ${ }^{2}$, Gerald Wetzel ${ }^{1}$, and Johannes Orphal ${ }^{1}$ \\ ${ }^{1}$ Karlsruhe Institute of Technology, Institute of Meteorology and Climate Research, Karlsruhe, Germany \\ ${ }^{2}$ National Research Council of Italy, Institute of Atmospheric Sciences and Climate, Bologna, Italy
}

Correspondence: Norbert Glatthor (norbert.glatthor@kit.edu)

Received: 15 February 2018 - Discussion started: 7 March 2018

Revised: 13 July 2018 - Accepted: 16 July 2018 - Published: 13 August 2018

\begin{abstract}
Discrepancies in ozone retrievals in MIPAS channels A $\left(685-970 \mathrm{~cm}^{-1}\right)$ and $\mathrm{AB}\left(1020-1170 \mathrm{~cm}^{-1}\right)$ have been a long-standing problem in MIPAS data analysis, amounting to an interchannel bias (AB-A) of up to $8 \%$ between ozone volume mixing ratios in the altitude range 30$40 \mathrm{~km}$. We discuss various candidate explanations, among them forward model and retrieval algorithm errors, interchannel calibration inconsistencies and spectroscopic data inconsistencies. We show that forward-modelling errors as well as errors in the retrieval algorithm can be ruled out as an explanation because the bias can be reproduced with an entirely independent retrieval algorithm (GEOFIT), relying on a different forward radiative transfer model. Instrumental and calibration issues can also be refuted as an explanation because ozone retrievals based on balloon-borne measurements with a different instrument (MIPAS-B) and an independent level-1 data processing scheme produce a rather similar interchannel bias. Thus, spectroscopic inconsistencies in the MIPAS database used for ozone retrieval are practically the only reason left. To further investigate this issue, we performed retrievals using additional spectroscopic databases. Various versions of the HITRAN database generally produced rather similar channel $\mathrm{AB}-\mathrm{A}$ differences. Use of a different database, namely GEISA-2015, led to similar results in channel $\mathrm{AB}$, but to even higher ozone volume mixing ratios for channel $\mathrm{A}$ retrievals, i.e. to a reversal of the bias. We show that the differences in MIPAS channel A retrievals result from about $13 \%$ lower air-broadening coefficients of the strongest lines in the GEISA-2015 database. Since the errors in line intensity of the major lines used in MIPAS channels $\mathrm{A}$ and $\mathrm{AB}$ are reported to be considerably
\end{abstract}

lower than the observed bias, we posit that a major part of the channel $\mathrm{AB}-\mathrm{A}$ differences can be attributed to inconsistent air-broadening coefficients as well. To corroborate this assumption we show some clearly inconsistent air-broadening coefficients in the HITRAN-2008 database. The interchannel bias in retrieved ozone amounts can be reduced by increasing the air-broadening coefficients of the lines in MIPAS channel $\mathrm{AB}$ in the HITRAN-2008 database by $6 \%-8 \%$.

\section{Introduction}

Ozone is one of the most important trace gases in the atmosphere. Stratospheric ozone to a large extent prevents solar ultraviolet (UV) radiation from reaching the Earth's surface. On the other hand, tropospheric ozone is a harmful air pollutant. Therefore knowledge of its atmospheric concentration is of high interest. Remote sensing of ozone is performed in a wide spectral range covering the microwave, infrared and ultraviolet regions. For measurements in the infrared the strong ozone $\nu_{3}$ band around $10 \mu \mathrm{m}$ is of particular interest. To obtain accurate atmospheric ozone volume mixing ratios (VMRs) high-quality line parameters are required. For this reason a large number of laboratory measurements have been taken. On the basis of three independent laboratory studies Flaud et al. (2003a) compiled a dedicated line list for the evaluation of MIPAS ozone measurements, which has been included in the HIgh-resolution TRANsmission database version 2004 (HITRAN-2004) (Rothman et al., 2005) and later ones. A review of various laboratory studies carried out over the past decades to determine ozone line in- 
tensities in the $9-11 \mu \mathrm{m}$ region has been given by Smith et al. (2012). According to these authors the goal of $1 \%$ absolute accuracy in line intensities, as demanded by Flaud and Bacis (1998), is not yet attained.

In the MIPAS spectroscopy, HITRAN version 2004 and later versions the ozone line intensities in the $10 \mu \mathrm{m}$ region were lowered by $4 \%$ compared to HITRAN-1996. Having been initiated by several more recent laboratory intercomparisons of ozone absorption coefficients in the mid-infrared and UV spectral regions (Picquet-Varrault et al., 2005; Gratien et al., 2010; Guinet et al., 2010), a debate was reopened on whether these ozone line intensities have to be increased by $3 \%-5 \%$ again. This is also supported by an intercomparison of total ozone columns by Schneider et al. (2008), who found a bias of $4 \%-5 \%$ between ground-based FTIR observations at $991-1007 \mathrm{~cm}^{-1}$ and Brewer measurements. A review of laboratory and field studies related to this topic was given by Orphal et al. (2016). However, rescaling of the ozone band intensities would only have an effect on the channel $\mathrm{AB}-\mathrm{A}$ bias observed in MIPAS data if the $\nu_{2}$ band used in channel A was not scaled by the same amount as the bands in the $10 \mu \mathrm{m}$ region applied in channel $\mathrm{AB}$ retrievals.

MIPAS measurements are taken in several channels covering the mid-infrared spectral region. Especially suited for MIPAS ozone retrieval is the strong fundamental $\nu_{3}$ band centred at $1042 \mathrm{~cm}^{-1}$, but also the weaker fundamental $v_{1}$ and $\nu_{2}$ bands at 1103 and $701 \mathrm{~cm}^{-1}$. While the $\nu_{1}$ and $\nu_{3}$ bands are mainly situated in MIPAS channel AB (1020$\left.1170 \mathrm{~cm}^{-1}\right)$, the $\nu_{2}$ band is located in channel A (685$970 \mathrm{~cm}^{-1}$ ). The fact that ozone retrievals using MIPAS channel AB $\left(1020-1170 \mathrm{~cm}^{-1}\right)$ microwindows (MWs) are biased high by up to $8 \%$ compared to retrievals based on MIPAS channel A $\left(685-970 \mathrm{~cm}^{-1}\right)$ MWs has already been reported by Glatthor et al. (2006) for measurements in the high spectral resolution mode (2002-2004), who concluded that the major part of the differences results from spectroscopic inconsistencies. These retrievals were performed using the ozone line list of the MIPAS database version pf 3.2 provided by Flaud et al. (2003b). The bias between MIPAS channel $\mathrm{A}$ and $\mathrm{AB}$ retrievals is of particular importance, because ozone data retrieved at IMK from a combination of channel $\mathrm{A}$ and $\mathrm{AB}$ microwindows (versions V5R_O3_220 and V5R_O3_221) have been found to be biased high in the altitude region around $40 \mathrm{~km}$ (Laeng et al., 2014). Since the uncertainties in line intensity of many strong lines - especially in the $\nu_{3}$ band - have been declared to be less than $2 \%$ (Wagner et al., 2002), the problem has been reassessed, and various potential reasons for the deviations have been examined.

In Sects. 2-3 we shortly describe the MIPAS experiment and the retrieval set-up, followed by a presentation of the ozone profiles resulting from retrievals using the MIPAS pf3.2 spectroscopy in Sect. 4. In Sects. 5-6 we show investigations which widely exclude forward-modelling, instrumental or calibration issues as reasons for the observed bias.
In Sect. 7.1 we apply the ozone line data of various versions of the HITRAN database. In Sect. 7.2 we present a comparison between retrievals using ozone lines of a completely different database, namely GEISA-2015 (JacquinetHusson et al., 2016) and retrievals based on the HITRAN2008 data. Then we demonstrate the possibility to reduce the channel $\mathrm{AB}-\mathrm{A}$ differences by changing the air-broadening coefficients (Sect. 7.3). In Sect. 8 we show internal inconsistencies of air-broadening coefficients in the HITRAN-2008 database, followed by a summary and conclusions in Sect. 9 .

\section{Instrument description and retrieval set-up}

The Michelson Interferometer for Passive Atmospheric Sounding (MIPAS), which was operated on board the ENVIronmental SATellite (ENVISAT) between 2002 and 2012, has been described in Fischer et al. (2008). Therefore we give only a short description of the instrument. MIPAS was a limb-viewing Fourier transform infrared emission spectrometer covering the spectral region between 685 and $2410 \mathrm{~cm}^{-1}$ (4.1-14.6 $\mu \mathrm{m})$. From June 2002 to April 2004 MIPAS has been operated in its original high spectral resolution (HR) mode and since January 2005 in reduced spectral resolution (RR) mode. We present retrievals based on data of the RR nominal measurement mode, which consisted of rearward limb-scans covering the altitude region between 7 and $72 \mathrm{~km}$ within 27 altitude steps. The level-1B radiance spectra used for retrieval are data versions 5.02/5.06 and 7.11 (reprocessed data) provided by the European Space Agency (ESA) (Nett et al., 2002). The IMK notation for these spectra versions is V5R and V7R.

To reinvestigate the channel $\mathrm{AB}-\mathrm{A}$ bias in retrieved ozone, retrievals using the processor of the Institut für Meteorologie und Klimaforschung and the Instituto de Astrofísica de Andalucía (IMK-IAA) were performed for 59 MIPAS orbits from 3 January, 1 April, 2 July and 2-3 October 2009. This processor uses the Karlsruhe Optimized and Precise Radiative Algorithm (KOPRA) (Stiller, 2000) for radiative transfer calculations and the Retrieval Control Program (RCP) by IMK-IAA for inverse modelling of spectra. Two microwindow set-ups were used, one in the spectral range of MIPAS channel $\mathrm{A}$ and the other in the range of channel $\mathrm{AB}$ (Tables 1,2). Both of the set-ups consist of a large number of 30 MWs that are used to obtain a high vertical resolution. The microwindows used in channel A span the wave number region $687-791 \mathrm{~cm}^{-1}$, covering the fundamental $\nu_{2}$ band, and those of channel $\mathrm{AB}$ span the region $1028-1164 \mathrm{~cm}^{-1}$, covering the fundamental $v_{1}$ and $v_{3}$ bands. The strong lines of the $v_{1}$ and $v_{3}$ bands are suited for ozone retrieval in the middle atmosphere, but in particular the $v_{3}$ lines become saturated for limb scans through the ozone concentration maximum at $\sim 28 \mathrm{~km}$ and through the lower stratosphere, where the $\nu_{2}$ lines are a suitable alternative. Consequently, the first four microwindows covering the central part of the $v_{3}$ band 
Table 1. Microwindow set used for ozone retrieval in MIPAS channel A. The left column shows the spectral ranges of the microwindows. The plus signs indicate at which heights a particular microwindow is used.

\begin{tabular}{|c|c|c|c|c|c|c|c|c|c|c|c|c|c|c|c|c|c|c|c|c|c|c|c|c|}
\hline \multirow[b]{2}{*}{ Microwindow $\left(\mathrm{cm}^{-1}\right)$} & \multicolumn{24}{|c|}{ Altitudes (km) } \\
\hline & 6 & 9 & 12 & 15 & 18 & 21 & 24 & 27 & 30 & 33 & 36 & 39 & 42 & 45 & 48 & 51 & 54 & 57 & 60 & 63 & 66 & 69 & 72 & 75 \\
\hline 687.6875-688.6875 & & & & & & & & & & + & & + & + & + & + & + & + & + & + & + & + & + & + & + \\
\hline $689.3125-691.8750$ & & & & & & & + & + & + & & & + & + & + & + & + & + & + & + & + & + & + & + & + \\
\hline $692.2500-695.1875$ & & & & & & & & & & & + & + & + & + & + & + & + & + & + & + & + & + & + & + \\
\hline $707.1250-710.0625$ & & & & & & & & + & + & + & + & + & + & + & + & + & + & + & + & + & + & + & + & + \\
\hline $712.3125-713.4375$ & + & + & + & & & & & & & & & + & + & + & + & & + & & & & & & & \\
\hline $713.5000-716.4375$ & + & + & + & & & & + & + & + & + & + & + & + & + & + & + & & + & + & + & + & + & + & + \\
\hline $716.5000-719.4375$ & & + & & & & & + & + & & + & + & + & + & + & + & + & + & + & + & + & + & + & + & + \\
\hline $720.7500-723.6875$ & & & + & & & & & + & + & + & + & + & + & + & + & + & + & + & + & + & + & + & + & + \\
\hline $728.5000-729.3750$ & + & + & & & & & & & & + & + & + & + & + & + & + & + & + & + & + & + & + & + & + \\
\hline $730.0625-730.5000$ & & + & + & & & & & & & + & + & + & + & + & + & + & + & + & + & + & + & + & + & + \\
\hline $731.9375-732.8750$ & + & + & & & & & + & + & + & & & + & & & & + & + & + & + & + & + & & + & + \\
\hline $734.0000-734.7500$ & + & + & & & & & & & & + & + & & + & + & + & + & + & & & & & + & + & + \\
\hline $736.4375-739.3750$ & + & + & & & + & + & & + & & + & + & + & + & + & + & + & + & + & + & + & + & + & + & + \\
\hline $739.4375-741.9375$ & + & + & & & & & & & + & + & + & + & + & + & + & + & + & + & + & + & + & + & + & + \\
\hline $745.2500-745.6875$ & + & & + & + & + & & & & & + & + & + & + & + & + & + & + & + & + & + & + & + & + & + \\
\hline $746.6875-747.1250$ & + & + & & + & & + & + & + & + & + & + & + & + & + & + & + & + & + & + & + & + & + & + & + \\
\hline $747.6250-748.3750$ & + & & & & & & & + & + & + & + & & + & + & + & + & + & & & & + & + & + & + \\
\hline $749.5625-752.5000$ & + & & & + & & + & + & + & + & + & + & + & + & + & + & + & + & + & + & + & + & + & + & + \\
\hline $752.9375-755.8750$ & & & & & + & + & + & & & + & + & + & + & + & + & + & + & + & + & + & + & + & + & + \\
\hline $758.3750-759.4375$ & & & & + & + & + & + & + & + & + & + & + & + & + & + & + & + & + & + & + & + & + & + & + \\
\hline $759.5000-761.8750$ & + & + & + & + & & & + & & & + & + & + & + & + & + & + & + & + & + & + & + & + & + & + \\
\hline $765.0000-765.6250$ & + & + & + & + & & & & & & & + & + & + & + & + & + & + & + & + & + & + & + & + & + \\
\hline $767.5000-768.0000$ & & + & + & + & + & + & + & + & + & + & + & + & + & + & + & + & + & + & + & + & + & + & + & + \\
\hline $771.8750-772.1250$ & + & & + & + & + & + & + & + & + & + & + & + & + & + & & & + & + & + & + & + & + & + & + \\
\hline $774.2500-774.5625$ & + & & & + & & + & + & + & & & + & + & + & + & & & + & & & & + & + & & \\
\hline $776.5000-776.7500$ & + & & & & & & & & & & & & + & + & & + & & + & + & + & + & + & & \\
\hline $780.2500-781.9375$ & + & + & + & + & + & & & & & + & + & + & + & + & + & + & + & + & + & + & + & + & + & + \\
\hline $788.9375-789.6875$ & + & + & + & + & + & & & & & + & + & + & + & + & + & + & + & + & + & + & + & + & + & + \\
\hline $790.7500-791.0000$ & + & & + & + & + & & & & & & & & & & + & & & & & & & & & \\
\hline $791.1875-791.5625$ & + & + & + & & + & + & & & & & + & + & + & + & + & + & + & + & + & + & + & + & + & + \\
\hline
\end{tabular}

are mostly omitted at these altitudes in the MW selection for channel AB retrievals because of saturation (Table 2). In addition to the lines of the fundamental bands, the spectral regions used for retrieval contain a large number of ozone lines from higher transitions.

Except for the use of dedicated microwindows restricted to MIPAS channels A or AB, the set-up is the same as for the IMK retrieval version O3_V5R_220, consisting of a joint-fit of ozone, microwindow-dependent continuum profiles and a microwindow-dependent, but height-constant spectral offset. Temperature, pressure and $\mathrm{H}_{2} \mathrm{O}$ profiles required for forward modelling were taken from preceding retrieval steps, and the profiles of the remaining interfering species were taken from the climatology provided by Remedios et al. (2007). For all but one retrieval test presented here, spectra of version V5R of the reduced spectral resolution period were taken. Since the subsequent set of MIPAS spectra (version V7R) was presumably produced using an improved calibration scheme, one additional channel $\mathrm{AB}-\mathrm{A}$ intercomparison was performed on the basis of this data set. While the spectroscopic data for ozone were changed in several tests, the same line lists were always used for all other gases. More information on trace gas retrieval from MIPAS data performed at IMK can be found in various papers, e.g. in von Clarmann et al. (2003) or in Höpfner et al. (2004).

\section{Error estimates of ozone line and band intensities}

As specified by Flaud and Piccolo (Jean-Marie Flaud, personal communication, 2002) the relative error SX in line intensity of ozone lines of the fundamental $v_{1}, v_{2}$ and $v_{3}$ bands in the MIPAS database can be parameterized as follows:

$\mathrm{SX}=0.02 \times(1+\mathrm{JU} / 70+\mathrm{KU} / 25)$,

where $\mathrm{JU}$ is the upper-state rotational $\mathrm{J}$ quantum number and $\mathrm{KU}$ the upper-state rotational $\mathrm{K}$ quantum number. For the other transitions ending at the ground state the error is

$\mathrm{SX}=0.03 \times(1+\mathrm{JU} / 60+\mathrm{KU} / 20)$.

For higher transitions the relative error gradually increases up to

$\mathrm{SX}=0.10 \times(1+\mathrm{JU} / 35+\mathrm{KU} / 11)$ 
Table 2. Microwindow set used for ozone retrieval in MIPAS channel AB. The left column shows the spectral ranges of the microwindows. The plus signs indicate at which heights a particular microwindow is used.

\begin{tabular}{|c|c|c|c|c|c|c|c|c|c|c|c|c|c|c|c|c|c|c|c|c|c|c|c|c|}
\hline \multirow[b]{2}{*}{ Microwindow $\left(\mathrm{cm}^{-1}\right)$} & \multicolumn{24}{|c|}{ Altitudes (km) } \\
\hline & 6 & 9 & 12 & 15 & 18 & 21 & 24 & 27 & 30 & 33 & 36 & 39 & 42 & 45 & 48 & 51 & 54 & 57 & 60 & 63 & 66 & 69 & 72 & 75 \\
\hline $1028.6875-1031.3750$ & & + & + & & & & & & & + & + & & & & & + & + & + & + & + & + & + & + & + \\
\hline $1037.9375-1040.8750$ & + & + & & & & & & & & + & + & & & & + & + & + & + & + & + & + & + & + & + \\
\hline $1044.6250-1044.9375$ & & & & & & & & & & & & & + & + & + & + & + & + & + & + & & & & + \\
\hline $1050.4375-1050.7500$ & & & & & & & & & & & + & + & & + & + & + & + & + & + & + & + & + & + & + \\
\hline $1070.4375-1070.7500$ & + & & & + & + & + & + & + & + & + & & & & & + & + & & & + & + & + & + & + & + \\
\hline $1072.0000-1072.3125$ & + & & + & & & + & + & + & + & + & + & + & + & + & + & + & + & & & + & + & & + & + \\
\hline $1073.6250-1074.4375$ & + & & & & & & + & + & + & + & + & + & + & & & & & & + & + & + & + & + & + \\
\hline $1074.7500-1075.8750$ & & & & & & & & & & + & + & + & + & + & + & + & + & + & + & + & + & + & + & + \\
\hline $1077.2500-1078.4375$ & & & & & + & + & + & + & + & + & + & + & + & + & + & + & + & + & + & + & + & & & + \\
\hline $1078.5000-1079.1250$ & & + & & + & + & + & & & & & & & & + & + & + & + & + & & & + & & & \\
\hline $1079.1875-1079.5625$ & & + & + & + & + & + & + & + & + & + & + & + & + & + & + & + & + & + & + & + & + & + & + & + \\
\hline $1081.1250-1083.4375$ & + & & & & & + & & & + & + & + & + & + & + & + & + & + & + & + & + & + & & & \\
\hline $1115.8125-1116.2500$ & & & & & & + & + & + & + & + & + & + & + & + & + & + & + & + & + & + & + & + & + & + \\
\hline $1117.1875-1117.4375$ & + & + & + & + & & & + & + & + & + & + & & + & & & + & + & + & + & + & + & + & + & + \\
\hline $1118.1250-1118.4375$ & + & + & & + & + & + & & & & + & + & + & + & + & + & & + & + & + & + & + & + & + & + \\
\hline $1119.6250-1119.8750$ & + & + & + & + & + & & + & + & + & & + & + & + & & & + & + & + & + & & & & & + \\
\hline $1122.6875-1123.1250$ & + & + & + & + & + & + & + & + & + & + & + & + & + & + & + & + & + & + & + & + & + & + & + & + \\
\hline $1124.8750-1125.1875$ & + & & & & & + & + & + & + & + & + & + & + & + & + & + & + & + & + & + & + & + & + & + \\
\hline $1126.1875-1126.4375$ & & + & + & + & + & + & + & + & + & & & & & & & & & & & & & & & \\
\hline $1127.2500-1127.5000$ & + & + & + & & + & & & & & & & & & & & & & & & & & & & \\
\hline $1127.8750-1128.3125$ & + & + & + & + & + & & & & + & + & + & + & & & + & + & + & + & + & + & + & + & + & + \\
\hline $1128.4375-1128.8125$ & + & + & + & + & + & + & + & + & & + & + & + & & & & + & + & + & + & + & & & + & + \\
\hline $1129.3125-1129.7500$ & + & + & + & + & + & + & + & + & + & + & + & + & & & & + & + & + & + & + & + & + & + & + \\
\hline $1131.2500-1134.1875$ & + & & + & + & & & + & + & + & + & + & + & + & + & + & + & + & + & + & + & + & + & + & + \\
\hline $1139.6875-1140.0625$ & + & + & & + & & + & + & + & + & + & + & + & + & + & + & + & + & + & + & + & + & + & + & + \\
\hline $1140.8750-1141.1250$ & + & + & + & + & + & + & + & & & + & + & + & + & + & & + & + & + & + & + & & & & + \\
\hline $1160.5625-1160.8125$ & & + & + & & & & & & + & + & & + & + & + & & & & & & & & + & + & \\
\hline $1160.9375-1161.3750$ & + & + & + & + & + & + & + & + & + & + & + & & & & + & + & + & + & + & + & + & & & + \\
\hline $1161.4375-1161.7500$ & + & + & + & + & + & + & + & + & + & + & & & & & & & & & & & & & & \\
\hline $1163.7500-1164.0625$ & & + & + & & & & + & + & + & + & + & + & + & + & + & + & + & + & + & + & + & + & + & + \\
\hline
\end{tabular}

for the transitions ending at strongly excited lower states.

The error estimates for ozone line intensities in the HITRAN-2008 database are of similar magnitude (Rothman et al., 2009). In the region of the channel A microwindows they are $1 \%-2 \%$ for the strongest lines, $2 \%-5 \%$ for lines of medium strength and 5\%-10\% for weak lines. For the lines in channel $\mathrm{AB}$ no error estimates are given for line intensities. The HITRAN-2008 error estimates for the airbroadened half widths vary between $2 \%$ and $5 \%$ for the strongest lines and between $10 \%$ and $20 \%$ for weak lines.

Due to the high accuracy in line intensities as outlined in the Introduction, a potential systematic offset between the ozone bands in MIPAS channels A and AB can be assumed to be lower than $2 \%$. This is also justified by the fact that one of the spectroscopic data sets that were used as basis for the ozone line lists in the MIPAS database as well as in all recent HITRAN compilations (version 2004 and later ones), consists of simultaneous laboratory measurements of the $v_{1}$, $v_{2}$ and $\nu_{3}$ band regions (Wagner et al., 2002).

\section{Retrievals using the MIPAS spectroscopy}

As already mentioned in the Introduction, a dedicated spectroscopic database for the analysis of MIPAS data was established by Flaud et al. (2003b). The starting point for this database was the HITRAN-1996 edition. The new line lists were validated by comparison between atmospheric simulations and ATMOS (Atmospheric Trace Molecule Spectroscopy) as well as MIPAS measurements. The focus of these investigations was a spectroscopic update of the main target species of MIPAS, namely $\mathrm{H}_{2} \mathrm{O}, \mathrm{CO}_{2}, \mathrm{O}_{3}, \mathrm{CH}_{4}, \mathrm{NO}_{2}$ and $\mathrm{HNO}_{3}$. The ozone spectroscopy was updated on the basis of three sets of highly consistent experimental data (Flaud et al., 2003a). More specifically, a new compilation of the fundamental $v_{1}, v_{2}$ and $v_{3}$ bands was created and complemented by all higher transitions contained in the HITRAN1996 database. Since the line intensities in the fundamental $v_{1}$ and $v_{3}$ bands of the new data set were about $4 \%$ lower than the corresponding intensities in HITRAN-1996, the line intensities of all bands adopted from HITRAN-1996 were divided by 1.04 .

Figure 1a shows average ozone profiles resulting from retrievals in MIPAS channels $\mathrm{A}$ and $\mathrm{AB}$ using the ozone line list of the MIPAS database version 3.2, which has also been 

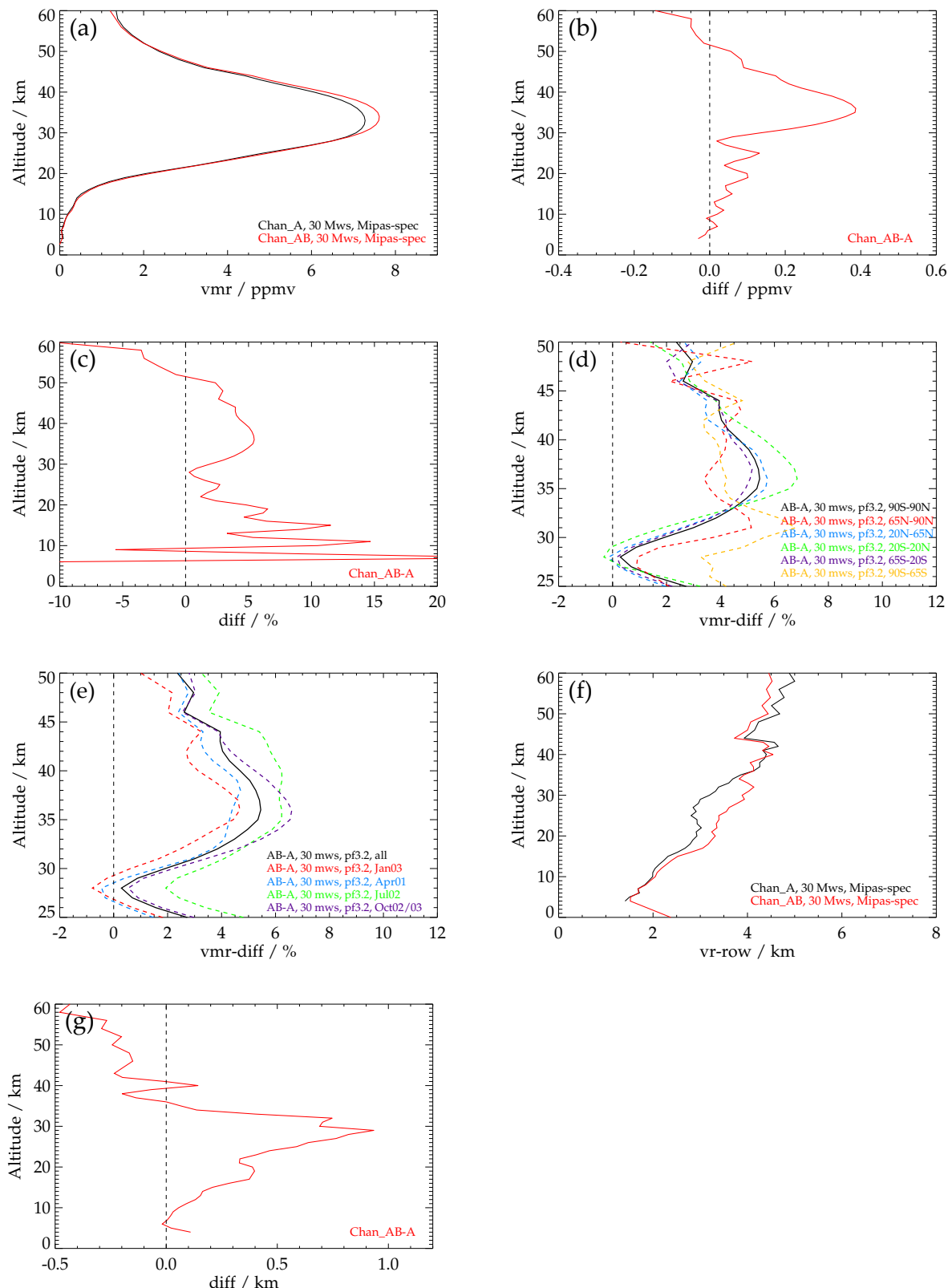

Figure 1. (a) Mean ozone profiles retrieved in MIPAS channels A (black) and AB (red) using the MIPAS pf3.2 spectroscopy. All profiles of 59 orbits from 3 January, 1 April, 2 July and 2-3 October 2009 were averaged. (b) Absolute and (c) relative differences between the profiles retrieved in channels $\mathrm{AB}$ and $\mathrm{A}$. (d) Relative AB-A differences for all data (solid line) and in the latitude bands $65-90^{\circ} \mathrm{N}, 20-65^{\circ} \mathrm{N}$, $20^{\circ} \mathrm{S}-20^{\circ} \mathrm{N}, 65-20^{\circ} \mathrm{S}$ and $90-65^{\circ} \mathrm{S}$ (dashed lines; see legend). (e) Relative AB-A differences for all data (solid line), 3 January, 12 April, 2 July and 2-3 October 2009 (dashed lines, see legend). Note the different height scales for the latitudinal and seasonal displays. (f) Mean vertical resolution of the MIPAS channel A (black) and AB retrievals (red). (g) Difference between the vertical resolution of MIPAS channel $\mathrm{AB}$ and $\mathrm{A}$ retrievals.

applied in an earlier investigation (Glatthor et al., 2006). This ozone line list is also applied for operational ozone retrieval at IMK-IAA. The profiles of all geolocations of the 59 evaluated orbits were averaged (see Sect. 2). Similarly to the previous investigation, use of the MIPAS spectroscopy leads to systematically higher ozone values using MIPAS channel
AB microwindows compared to channel A MWs. The absolute differences are largest in the height region $28-45 \mathrm{~km}$ and amount to $0.4 \mathrm{ppmv}$ at $36 \mathrm{~km}$ altitude (Fig. 1b), which corresponds to a relative difference of $6 \%$ (Fig. 1c). This difference is larger than the relative error in line intensity given in Eqs. (1) and (2) for the strongest and medium-scale ozone 
lines (at least for transitions with low to medium-sized rotational quanta JU and $\mathrm{KU}$ ). The large scatter of the relative differences below $20 \mathrm{~km}$ is caused by the much lower ozone VMRs and by averaging of increasingly fewer values due to cloud filtering. For different latitude bands (Fig. 1d) or seasons (Fig. 1e) the relative differences in the altitude range 30 to $45 \mathrm{~km}$ vary between $5 \%$ and $7.5 \%$.

The vertical resolution in terms of full width at half maximum (FWHM) in channel $\mathrm{AB}$ is up to $1 \mathrm{~km}$ worse than in channel $A$ between 10 and $35 \mathrm{~km}$ altitude, nearly the same between 35 and $40 \mathrm{~km}$ and up to $0.5 \mathrm{~km}$ better above $40 \mathrm{~km}$ (Fig. 1f, g). This shows the somewhat better appropriateness of channel A microwindows for ozone retrieval in the lower stratosphere and of channel AB microwindows in the upper stratosphere and mesosphere. The effect of the differences in height resolution on the retrieved VMRs was tested by application of the averaging kernels from channel A retrievals to channel $\mathrm{AB}$ profiles and vice versa. This led to negligible changes in the profiles only (not shown).

The corresponding ozone profile of the most actual IMK ozone data version using V5R-spectra (V5R_O3_224.1) is practically identical to the channel A result presented here. The reason is a nearly identical set of microwindows used for the standard retrieval. The almost complete restriction to channel A microwindows (except of two channel AB MWs used above $50 \mathrm{~km}$ ) resulted from a validation study (Laeng et al., 2014). This study had shown that the earlier ozone data version V5R_O3_220.1 was biased high in the altitude range $35-45 \mathrm{~km}$ due to a higher fraction of channel AB microwindows, applied at $36 \mathrm{~km}$ and above.

\section{Exclusion of forward-modelling issues}

Similar ozone retrievals with microwindows situated in MIPAS channels $A$ or $A B$ were also performed with the Bologna geo-fit multitarget retrieval model (GMTR), which uses a different forward model (Carlotti et al., 2006). The differences between channel $\mathrm{A}$ and $\mathrm{AB}$ retrievals are very similar to those resulting from the IMK-IAA retrievals (Fig. 2). This agreement widely excludes the hypothesis that the bias is caused by deficiencies in the KOPRA forward model used at IMK. Nevertheless, a number of possible forwardmodelling issues have been investigated and are discussed below.

Channel-dependent accuracy parameters: To check whether the higher ozone amounts retrieved in MIPAS channel $\mathrm{AB}$ are caused by a disproportionately high rejection of weak lines by KOPRA when modelling the absorption coefficients in this spectral region, channel $A B$ retrievals were performed with strongly increased accuracy in the calculation of the absorption coefficients. This leads to better consideration of weak lines. However, these retrievals resulted in nearly identical ozone profiles (not shown).
Channel-dependent continua: Since the continuum profiles fitted in the first four microwindows of the dedicated channel AB occupation matrix often exhibit unphysical negative excursions in the altitude region 35 to $40 \mathrm{~km}$, additional channel $\mathrm{AB}$ retrievals were performed without these microwindows. The effect on the retrieved ozone profiles was negligible (not shown).

Non-local thermodynamic equilibrium (NLTE) effects: Another possible reason for the bias in ozone VMRs could be different strengths of NLTE effects on MIPAS channel $A$ and $\mathrm{AB}$ retrievals. Like for standard MIPAS ozone retrievals from nominal mode measurements, time-consuming modelling of NLTE effects was not taken into account for the channel $A$ and $A B$ retrievals. This is generally justified because these effects are mostly small in the stratosphere, and spectral regions subject to NLTE effects are avoided in the microwindow selection. Nevertheless, channel A and AB ozone retrievals including modelling NLTE effects had been performed by Glatthor et al. (2006), who had shown that the neglect of NLTE modelling is not the dominant reason for the channel AB-A bias. Such calculations were not repeated here. Instead, since NLTE conditions generally persist during the daytime, day- and night-time profiles of the data set were averaged separately (Fig. 3). It is evident that the channel $\mathrm{AB}-\mathrm{A}$ differences are nearly the same for the whole data set as well as for the day- and night-time measurements. According to this estimation, NLTE effects have only little influence on the observed differences.

Non-Voigt line shape: As commonly done in radiative transfer calculations for space-borne mid-IR measurements, line modelling with KOPRA is performed assuming a Voigt line shape. This assumption is confirmed by Tran et al. (2010), who showed that for the entire $10 \mu \mathrm{m}$ ozone band non-Voigt line shape effects, represented by a speeddependent Voigt model, lead to errors in retrieved atmospheric ozone of less than $1 \%$. These investigations were based on calculated as well as on measured spectra obtained by limb-viewing solar occultation and emission measurements. Therefore, we conclude that the channel AB-A bias for the most part cannot be explained by the neglect of nonVoigt effects.

\section{Exclusion of instrumental and calibration issues}

To exclude instrumental or calibration issues, ozone retrievals using channel $\mathrm{A}$ and $\mathrm{AB}$ microwindows were also performed for measurements of the MIPAS-balloon instrument (Friedl-Vallon et al., 2004), i.e. for a completely independent experiment with different level-1 processing and calibration procedures (Fig. 4). The balloon spectra were obtained on 31 March 2011 over Esrange, Sweden $\left(67.9^{\circ} \mathrm{N}\right.$, $\left.21.1^{\circ} \mathrm{E}\right)$ and on 14 June 2005 over Teresina, Brazil $\left(5.1^{\circ} \mathrm{S}\right.$, $\left.42.9^{\circ} \mathrm{W}\right)$. These retrievals resulted in channel AB-A differences of $0.5 \mathrm{ppmv}$ in the altitude range of $30-40 \mathrm{~km}$, which 

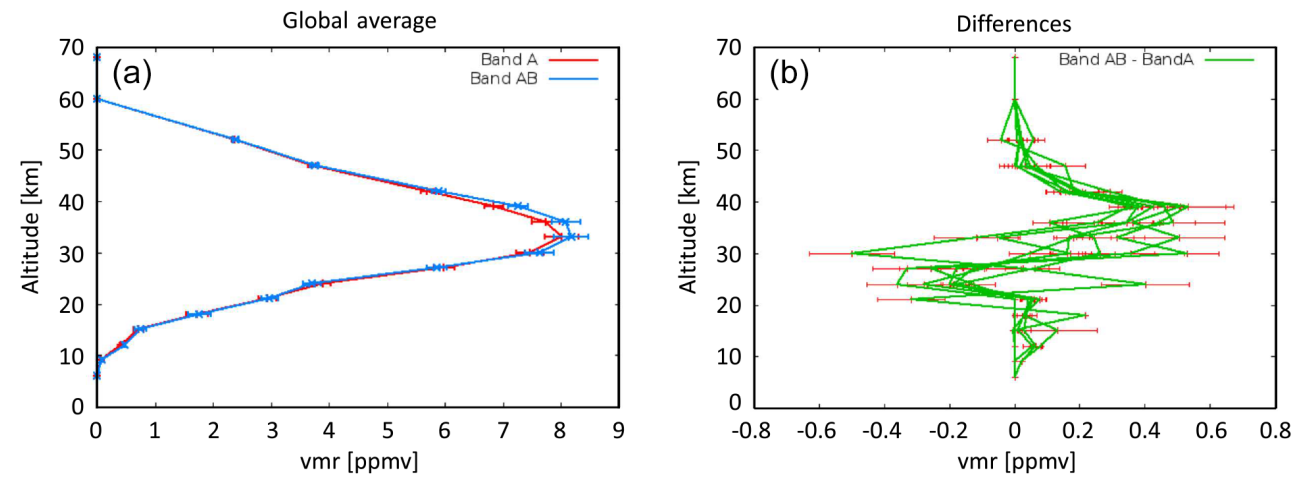

Figure 2. (a) Mean ozone profiles of MIPAS orbits 2633 and 2634 retrieved with the Bologna geo-fit multitarget retrieval model (GMTR) using microwindows in MIPAS channels A (red) and AB (blue). (b) Respective AB-A differences for several latitude bands.

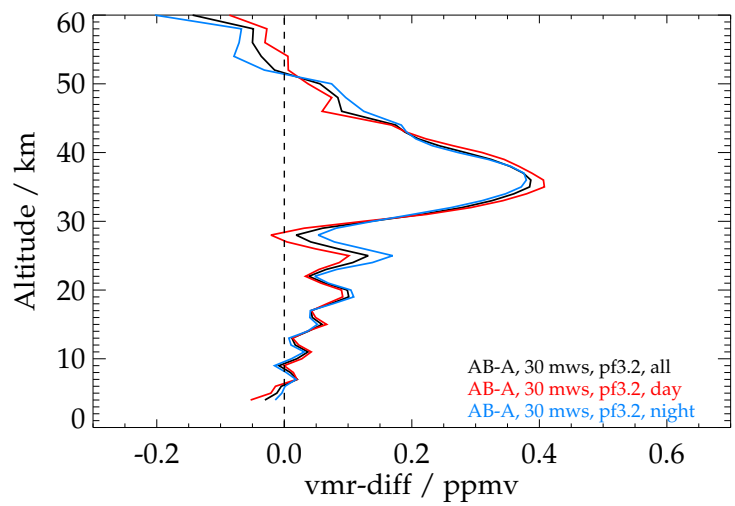

Figure 3. Difference between mean ozone profiles retrieved in MIPAS channels AB and A using the MIPAS pf3.2 spectroscopy. The profiles are averages over 59 orbits from 3 January, 1 April, 2 July and 2-3 October 2009 for all (black), daytime (red) and night-time profiles (blue).

are similar to those found in the space-borne MIPAS observations. This agreement largely excludes inconsistencies in calibration of channel A and AB spectra, different detector alignment or instrumental line shape issues in the spaceborne MIPAS data. Nevertheless, instrumental and calibration issues have been investigated, and the most important ones are shortly discussed below.

Spectral calibration issues: To check deficiencies in spectral calibration, ozone retrievals were also performed with MIPAS spectra version V7R, which had been generated with an improved calibration scheme. However, this test resulted in even somewhat larger channel $\mathrm{AB}-\mathrm{A}$ differences than retrievals with MIPAS V5R spectra (see Fig. 5).

Line of sight issues: The vertical field of view of the MIPAS experiment is assumed to be the same for each channel. However, due to detector misalignment, the effective line of sight might vary between the different MIPAS channels. Although a detector misalignment is widely excluded by the similarity of the MIPAS-balloon results, this problem has
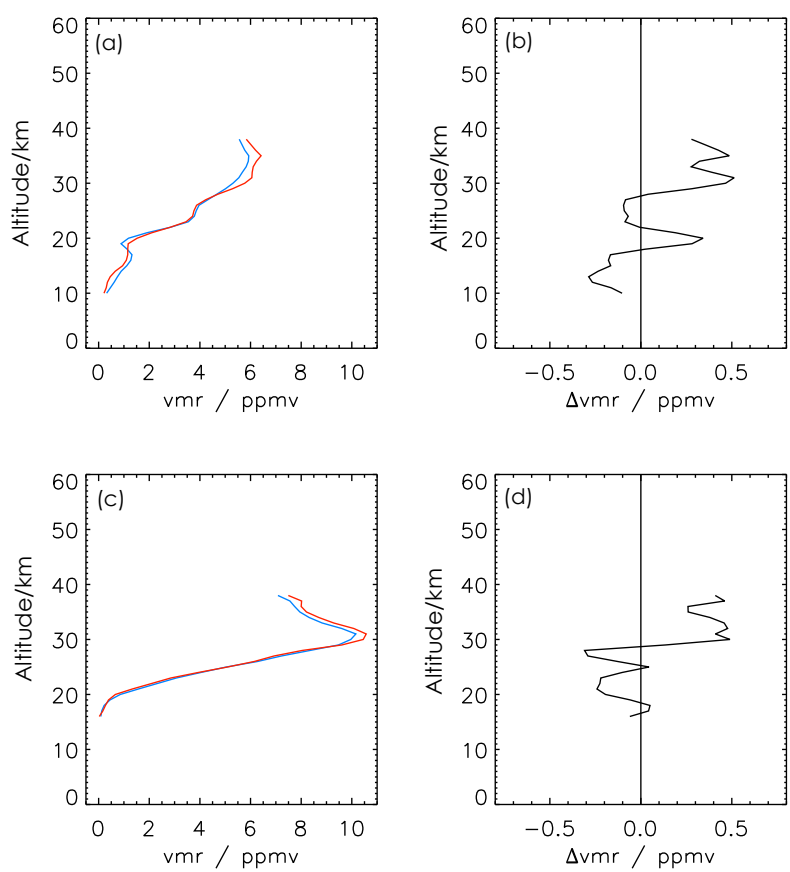

Figure 4. (a) Ozone profiles retrieved from MIPAS-balloon measurements above Esrange $\left(67.9^{\circ} \mathrm{N}, 21.1^{\circ} \mathrm{E}\right)$, Sweden, on 31 March 2011, using microwindows in MIPAS channels A (blue) and $\mathrm{AB}$ (red). (b) Difference between retrievals using microwindows in MIPAS channels AB and A. (c) Same as (a) but for MIPASballoon measurements above Teresina $\left(5.1^{\circ} \mathrm{S}, 42.9^{\circ} \mathrm{W}\right)$, Brazil, on 14 June 2005. (d) Differences between the ozone profiles resulting from use of the modified and the original HITRAN-2008 spectroscopy.

been investigated. It turned out that the field of view of channel $\mathrm{AB}$ would have to be shifted upward by more than $500 \mathrm{~m}$ to remove the channel $\mathrm{AB}-\mathrm{A}$ differences in the height region $33-40 \mathrm{~km}$ (not shown). This shift is much larger than the instrumental requirement for interchannel co-alignment, which is $1.3 \mathrm{mdeg}$ or $68 \mathrm{~m}$, and therefore rather unrealistic. Thus, 

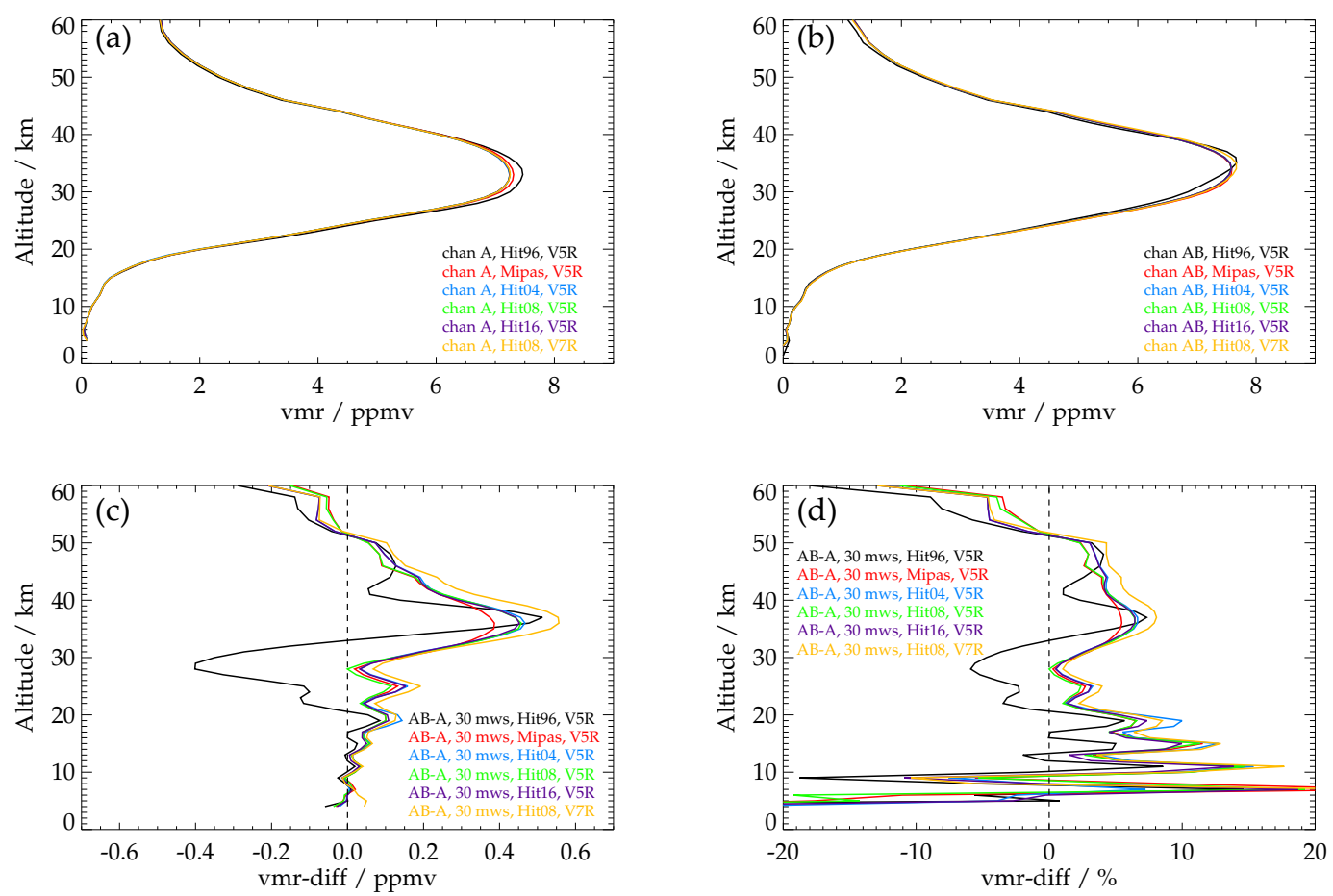

Figure 5. (a) Average ozone profiles retrieved in MIPAS channel A using V5R spectra and different spectroscopies: HITRAN-1996 (black), MIPAS pf3.2 (red), HITRAN-2004 (blue), HITRAN-2008 (green) and HITRAN-2016 (violet). The yellow curve shows the average profile for V7R spectra and application of the HITRAN-2008 line list. (b) Same as A, but for MIPAS channel AB. (c) Absolute and (d) relative differences between the profiles retrieved in channels $\mathrm{AB}$ and $\mathrm{A}$. The ozone profiles were averaged over all single-scan profiles of 59 orbits from 3 January, 1 April, 2 July and 2-3 October 2009.

this investigation confirms that interchannel misalignment is not the cause of the channel $\mathrm{AB}-\mathrm{A}$ bias.

\section{Retrievals using additional spectroscopic databases}

Since deficiencies in forward-modelling, instrumental and calibration issues can largely be ruled out as reason for the bias between channels $\mathrm{A}$ and $\mathrm{AB}$, inconsistencies in spectroscopic data practically are the only explanation left. For this reason we performed additional ozone retrievals using different HITRAN versions and the GEISA-2015 database to check whether there is any line list which produces more consistent ozone profiles for channel $\mathrm{A}$ and $\mathrm{AB}$ retrievals.

\subsection{Comparison of different HITRAN-versions}

Figure 5 shows average ozone profiles and channel $\mathrm{AB}-\mathrm{A}$ differences for retrievals using ozone line lists of versions 1996, 2004, 2008 and 2016 of the HITRAN spectroscopic database (Gordon et al., 2017, and references therein) as well as of the MIPAS spectroscopy. Retrievals performed with ozone line data of HITRAN versions 2000 and 2012 are not shown, because these line lists are practically identical to HITRAN-1996 and to HITRAN-2008, respectively. HITRAN versions 2004, 2008 and 2016 lead to nearly the same channel A (Fig. 5a) and channel AB profiles (Fig. 5b) as the MIPAS spectroscopy. Therefore these HITRAN versions also result in almost the same channel AB-A differences (Fig. 5c, d). For each of these databases the maximum difference is $0.5 \mathrm{ppmv}(7 \%)$ at the altitude of $36 \mathrm{~km}$, which is even somewhat larger than the bias resulting from the MIPAS spectroscopy. Consequently, these differences are also larger than the relative errors in line intensity given in Eqs. (1) and (2). Only the HITRAN-1996 spectroscopy leads to a somewhat different result, namely positive channel ABA differences of up to $0.5 \mathrm{ppmv}$ above $32 \mathrm{~km}$, but negative differences of up to -0.4 ppmv below this altitude. Similar results from using the HITRAN-1996 spectroscopy have already been shown by Glatthor et al. (2006). Since the correction scheme of detector non-linearities is assumed to be improved when generating MIPAS V7R spectra, an additional retrieval test was carried out using this data set and HITRAN 2008 line data. However, these spectra lead to even somewhat larger differences (yellow curve) than the V5R spectra.

The rather good agreement between the different channel $\mathrm{A}$ as well as channel $\mathrm{AB}$ retrievals indicates largely consistent spectroscopic parameters of corresponding ozone lines in the MIPAS spectroscopy and the HITRAN-2004 database as well as in later HITRAN versions for the spectral range of the channel $\mathrm{A}$ and $\mathrm{AB}$ microwindows. Therefore a compari- 
son between the line parameters of the MIPAS and HITRAN databases is not presented here but provided as a Supplement only.

\subsection{HITRAN-2008 versus GEISA-2015}

Since the channel AB-A bias could not be removed by using any of the HITRAN line lists, we carried out an additional retrieval test with a different spectroscopic database, namely the Gestion et Etude des Informations Spectroscopiques Atmosphériques - version 2015 (GEISA-2015) compilation (Jacquinet-Husson et al., 2016) and compared the results with those based on HITRAN-2008. Although the line parameters of the three fundamental ozone bands in GEISA2015 are principally obtained from the same sources as those in HITRAN-2008 (Jacquinet-Husson et al., 2008, and references therein), we found considerable differences.

\subsubsection{Retrieval results}

Figure 6 shows average ozone profiles resulting from retrieval in MIPAS channels $\mathrm{A}$ and $\mathrm{AB}$ using the ozone line lists of HITRAN-2008 (see Fig. 5) and of GEISA-2015. The GEISA-2015 database leads to nearly the same profile as HITRAN-2008 for retrievals using the channel $\mathrm{AB}$ microwindows but to even higher ozone VMRs for retrievals using the MWs in channel A, i.e. to a reversal of the bias obtained with the HITRAN line data. The differences between channel $\mathrm{AB}$ and A profiles obtained with the GEISA-2015 spectroscopy are negative in the height region $20-43 \mathrm{~km}$, amounting up to $-0.55 \mathrm{ppmv}$ or $-7.5 \%$ at $28 \mathrm{~km}$ altitude. Moreover, the differences between the channel A retrievals, which definitely have spectroscopic causes, are even larger and amount to $0.8 \mathrm{ppmv}$ or about $10 \%$. With regard to the validation study by Laeng et al. (2014) the channel A profiles obtained with the GEISA-2015 spectroscopy are most probably biased high.

\subsubsection{Comparison of spectral parameters}

The retrieval results indicate mostly consistent spectral parameters in HITRAN-2008 and GEISA-2015 for the ozone lines used in MIPAS channel AB, but considerable spectroscopic differences in the region of the channel A microwindows. In the following, we will compare the HITRAN-2008 and GEISA-2015 ozone lines applied in channel A as well as in channel $\mathrm{AB}$ to identify the parameters responsible for these differences.

First of all we compared the number of ozone lines of the two databases in the spectral region covered by the channel A microwindows. In this wave number region the GEISA2015 database contains 3631 lines, all of them having a corresponding line in the HITRAN-2008 edition. The latter contains 734 additional lines, which, however, are rather weak. Their intensities are between $2.013 \times 10^{-26}$ and $5.858 \times$ $10^{-24} \mathrm{~cm}^{-1} /\left(\right.$ molecule $\left.\mathrm{cm}^{-2}\right)$, while a considerable number of the lines contained in both databases have intensities between $1 \times 10^{-22}$ and $1.66 \times 10^{-21} \mathrm{~cm}^{-1} /\left(\right.$ molecule $\left.\mathrm{cm}^{-2}\right)$. A test retrieval without these additional lines (not shown) resulted in nearly the same ozone profiles as the retrieval using the complete HITRAN-2008 ozone line list. In the spectral range of the channel $\mathrm{AB}$ microwindows, the GEISA-2015 and HITRAN-2008 databases contain 3737 and 3804 lines, respectively. The number of corresponding lines is 3724 ; i.e. the HITRAN-2008 edition contains 80 lines, which are not in the GEISA-2015 compilation. Again, these lines have intensities below $9.21 \times 10^{-25} \mathrm{~cm}^{-1} /\left(\right.$ molecule $\mathrm{cm}^{-2}$ ) only, while a lot of the lines, which are available in both databases, have much higher intensities between $1 \times 10^{-22}$ and $3.9 \times$ $10^{-20} \mathrm{~cm}^{-1} /\left(\right.$ molecule $\left.\mathrm{cm}^{-2}\right)$. In summary, the strong lines which make sizable contributions to the spectra are included in both data sets, and the missing weak lines are ruled out as the cause of the discrepancy under investigation.

The spectral parameters which have the largest potential to cause a disagreement in channel A are line positions, line intensities or air-broadened half widths. Further parameters required for line modelling are lower state energies, the coefficients of temperature dependence of the air-broadened half widths and air-broadened pressure shifts. A comparison shows that the line positions and lower state energies of all GEISA-2015 and HITRAN-2008 lines inside the channel A microwindows agree exactly. Inside the channel AB MWs these parameters differ slightly between the two databases, but for a small number of very weak lines only. Compared to air-broadening, the relative contribution of self-broadening is of the order of $10^{-5}$ only and thus negligible. The pressure shift of the ozone lines in GEISA-2015 and most of the HITRAN-2008 lines used in channels $A$ and $A B$ is zero. About one-third of the HITRAN-2008 lines have weak shifts of only -0.0008 and $-0.0007 \mathrm{~cm}^{-1}$ in channels $A$ and $A B$, respectively. Thus, differences in pressure shift are also negligible. The remaining parameters are line intensities and airbroadened half widths.

Figure 7 shows the relative differences between the intensities of the ozone lines of the GEISA-2015 and the HITRAN-2008 database used for channel $\mathrm{A}$ and $\mathrm{AB}$ retrievals. It is evident that the intensities of the strongest lines used in channel A are practically identical. There are slight deviations of $5 \%$ for a part of the weaker lines only. This indicates that the differences in channel A retrievals do not result from inconsistent line strengths. The respective difference plot of the lines used in MIPAS channel AB also shows nearly identical intensities of the strongest lines. Again there are differences of $+5 \%$ for weaker lines and larger differences of up to $\pm 25 \%$ for very weak lines. However, the good agreement of the channel $\mathrm{AB}$ profiles (Fig. 6) shows that a potential influence of the different line strengths of the weak lines is low.

Next we correlated the air-broadened half widths $\gamma_{\mathrm{air}, 0}$ of the ozone lines used for channel $\mathrm{A}$ and $\mathrm{AB}$ retrievals of the two databases, colour-coded by the respective line 

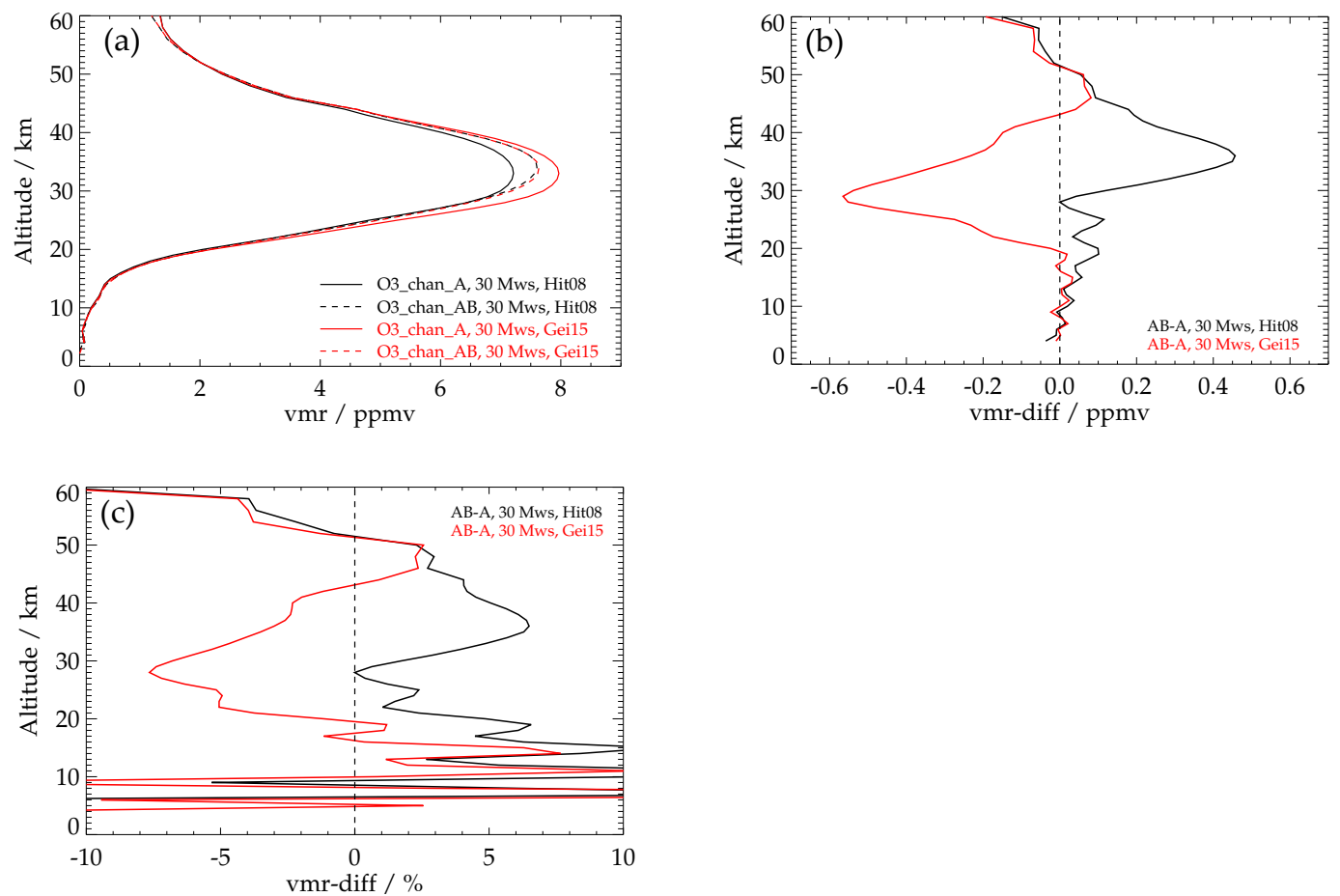

Figure 6. (a) Mean ozone profiles retrieved in MIPAS channels A (solid lines) and AB (dashed lines) using the HITRAN-2008 (black) and GEISA-2015 spectroscopy (red). The profiles are averages over 59 orbits from 3 January, 1 April, 2 July and 2-3 October 2009. (b) Absolute and (c) relative differences between the profiles retrieved in channels AB and A using HITRAN-2008 (black) and GEISA-2015 (red).
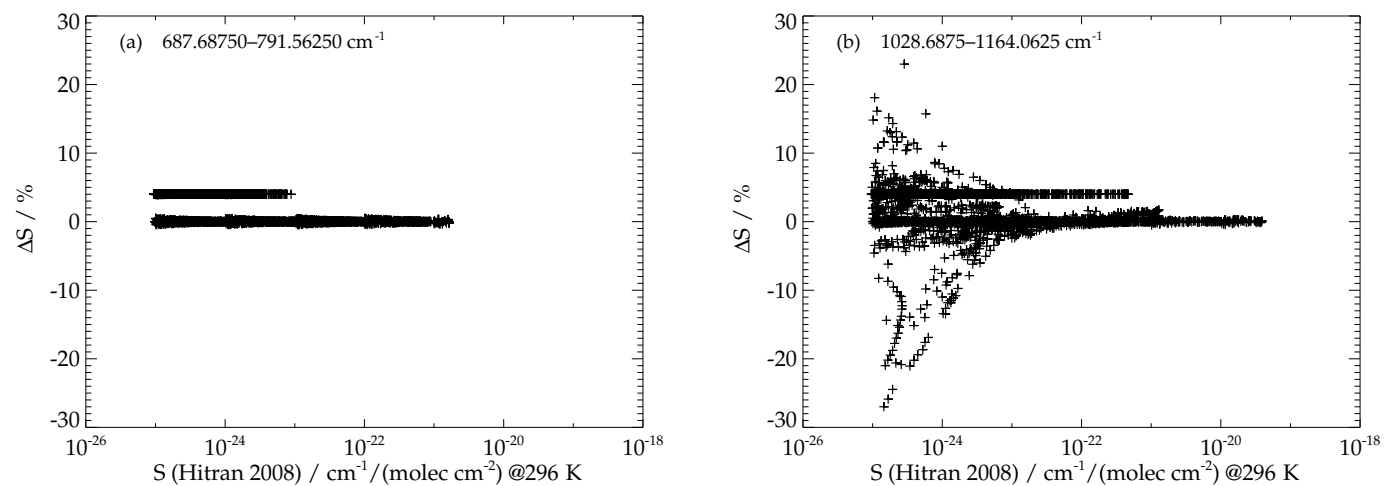

Figure 7. Relative differences $\Delta S$ between ozone line intensities of GEISA-2015 and HITRAN-2008 for the microwindows in MIPAS channel A (a) and AB (b).

strengths (Fig. 8). In both cases the air-broadened half widths of the HITRAN-2008 ozone lines are larger than those of the GEISA-2015 compilation, but there are clear systematic differences between the channel $\mathrm{A}$ and channel $\mathrm{AB}$ correlations for the strongest lines. In channel $A B$ the air-broadened half widths of the strongest lines are largely identical. However in channel A the $\gamma_{\text {air, } 0}$ values of the strongest lines are significantly lower $(\sim 13 \%)$ in the GEISA-2015 database. Differences between line-broadening parameters in the GEISA and HITRAN databases have already been reported by JacquinetHusson et al. (2008, 2011).
The air-broadened half widths $\gamma_{\text {air, } 0}$ given in the line databases are reference values for $p_{0}=1013.25 \mathrm{hPa}$ and $T_{0}=296 \mathrm{~K}$. The $\gamma_{\text {air }}$ values for actual temperature $T$ and pressure $p$ are calculated as follows:

$\gamma_{\text {air }}(p, T)=\gamma_{\text {air, } 0} \times p / p_{0}\left(T_{0} / T\right)^{n}$.

The coefficients $n$ of temperature dependence are also given in the spectroscopic databases. Figure 9 shows a scatter plot of the coefficients $n$ of GEISA-2015 versus HITRAN2008, again colour-coded by line strength. In channel A the 

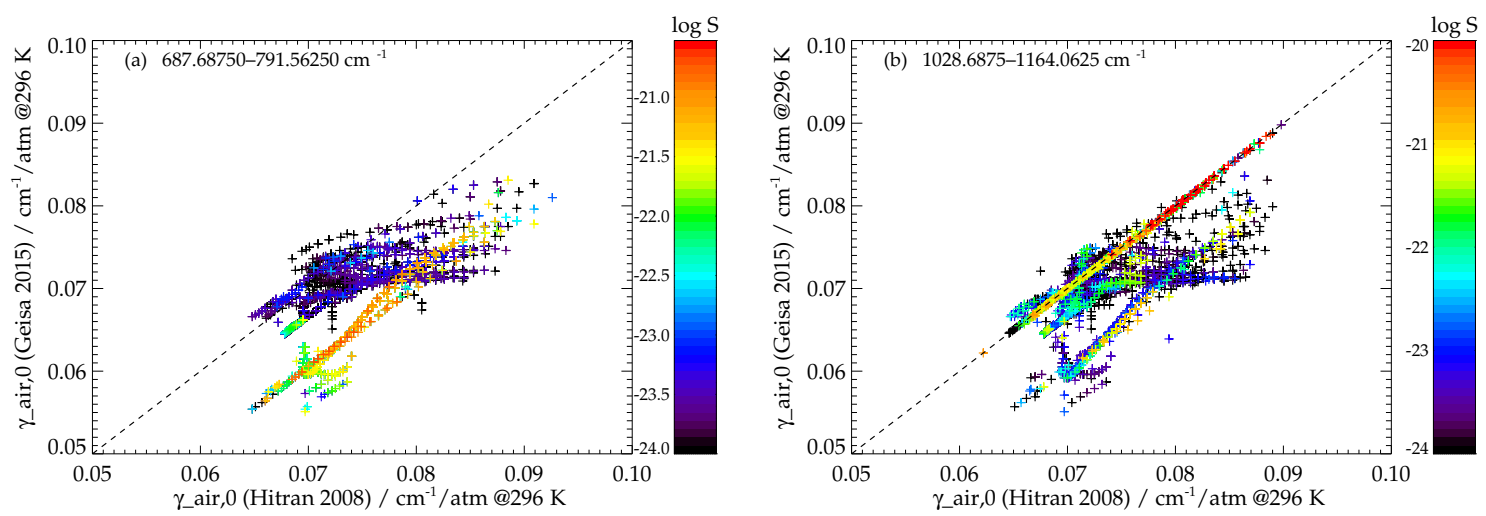

Figure 8. (a) Air-broadened half widths $\gamma_{\text {air }, 0}$ of GEISA-2015 versus HITRAN-2008 for the microwindows in MIPAS channel A. (b) Same as on the left, but for the microwindows in channel AB. The half widths are colour-coded by the logarithm of the HITRAN-2008 line intensities.
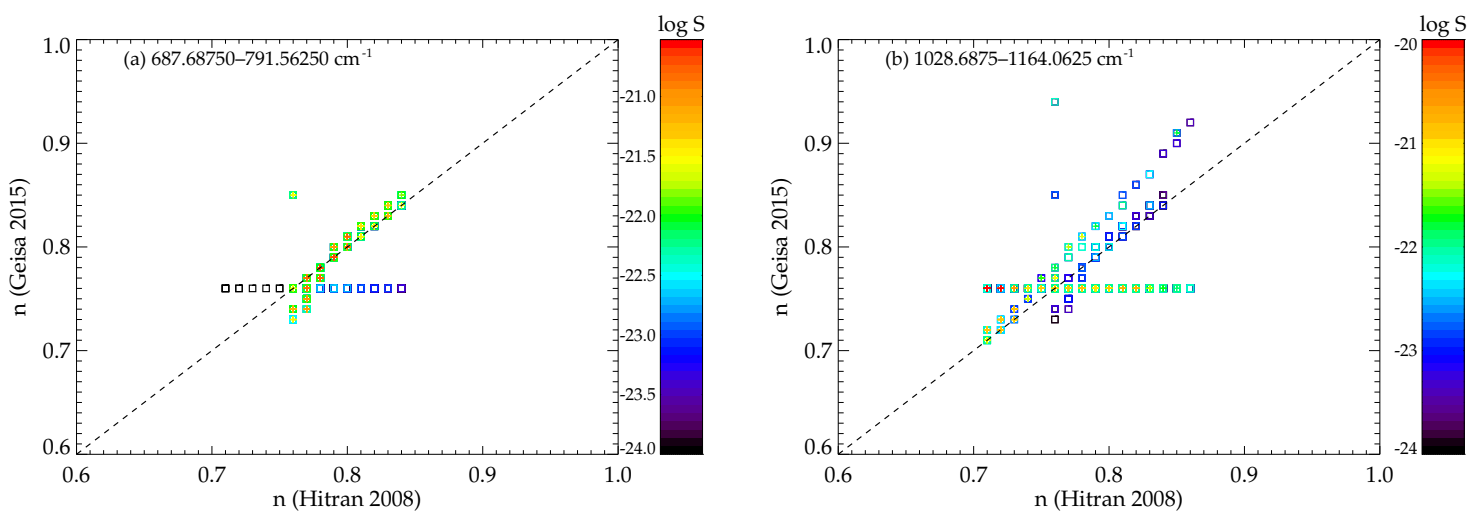

Figure 9. (a) Coefficients $n$ of temperature dependence of the air-broadened half widths of GEISA-2015 versus HITRAN-2008 for the microwindows in MIPAS channel A. (b) Same as on the left but for the microwindows in channel AB. The coefficients are colour-coded by the logarithm of the HITRAN-2008 line intensities. Plotted squares and pluses denote coefficients associated with line strengths lower or larger than $1 \times 10^{-22} \mathrm{~cm}^{-1} /\left(\right.$ molecule $\left.\mathrm{cm}^{-2}\right)$ at $296 \mathrm{~K}$.

coefficients $n$ of the strongest lines are nearly equal for both databases. Thus there is no compensation for the large differences in the air-broadened half widths of channel A via the coefficients $n$. In channel AB there are somewhat larger differences in some of the coefficients $n$ belonging to the strongest lines, namely the coefficients at the ordinate value of 0.76. However, since the channel AB profiles are nearly identical, these deviations obviously have no large effect. For example, a shift in the HITRAN-2008 values of 0.71 of several strong lines (red pluses) to the main diagonal changes $\gamma_{\text {air }}$ by $1.3 \%$ only for a stratospheric temperature of $230 \mathrm{~K}$.

The correlation analysis gives a strong indication that the differences in the ozone VMRs resulting from retrieval in channel A using HITRAN-2008 or GEISA-2015 data are not caused by differences in line strengths but rather by the differences between the air-broadened half widths of the strongest lines. To check this assumption we replaced the $\gamma_{\text {air, }, 0}$ values and the coefficients $n$ of temperature dependence in the GEISA-2015 database by the respective HITRAN-
2008 values and performed additional retrievals using these line parameters. Figure 10 shows the channel $\mathrm{A}$ and $\mathrm{AB}$ retrieval results using the original and the modified line list. After modification of the GEISA-2015 data the average ozone profile retrieved in channel $\mathrm{A}$ is nearly identical to the profile resulting from the HITRAN-2008 spectroscopy. This result confirms that the bias in channel A retrievals between use of the HITRAN-2008 and of the GEISA-2015 database is caused by the differences in air-broadened half widths. Furthermore, the small differences between the retrievals in channel $\mathrm{AB}$ are even more reduced.

\subsection{Channel AB retrievals using modified HITRAN-2008 lines}

Since the relative differences between the intensities of the ozone bands in MIPAS channels $\mathrm{A}$ and $\mathrm{AB}$ are assumed to be very small $(1 \%-2 \%)$, we posit that a considerable part of the database-internal channel $\mathrm{AB}-\mathrm{A}$ biases might be caused 

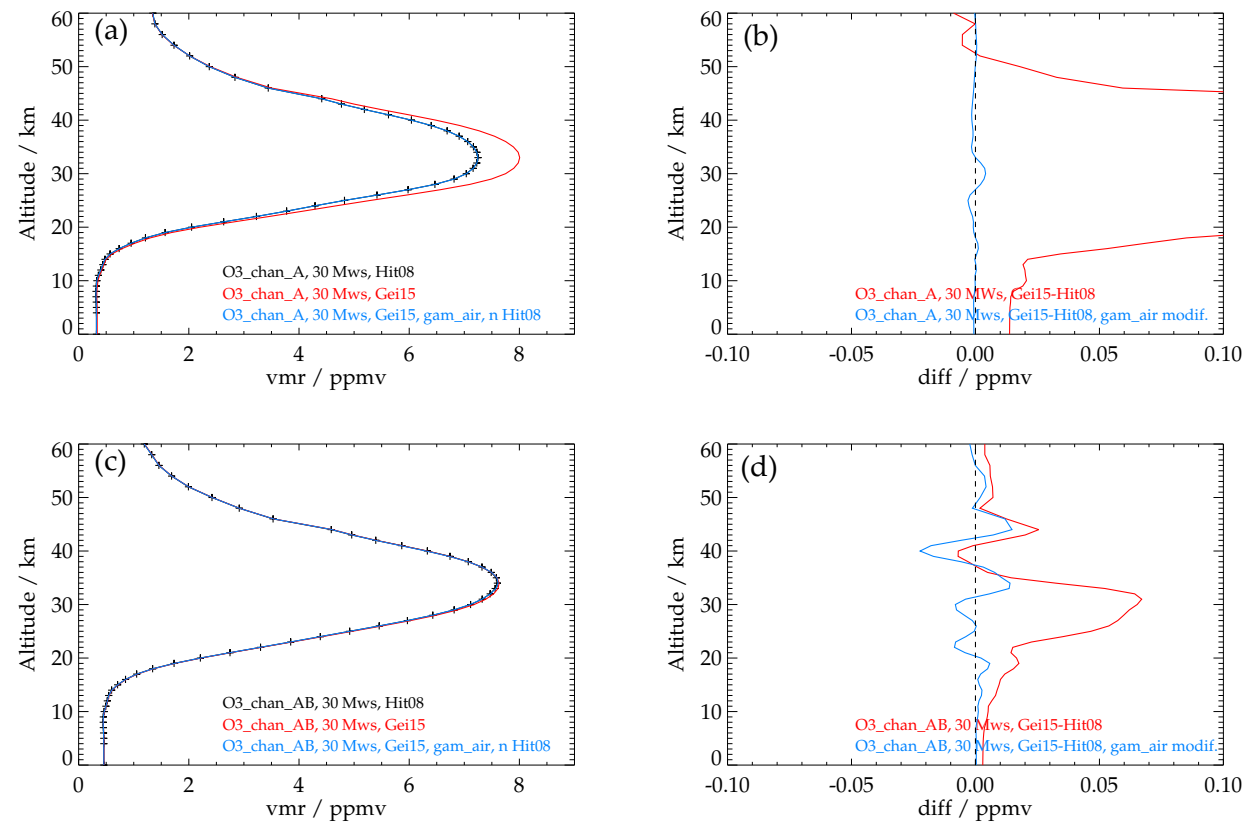

Figure 10. (a) Mean ozone profiles of 59 orbits from 3 January, 1 April, 2 July and 2-3 October 2009, retrieved in MIPAS channel A using the HITRAN-2008 (black), the GEISA-2015 (red) and a modified GEISA-2015 spectroscopy (blue). The modification consists of replacing the air-broadened half widths and coefficients of temperature dependence by the HITRAN-2008 values. (b) Corresponding differences to the ozone profile resulting from use of the HITRAN-2008 spectroscopy. (c) Same as (a) but for MIPAS channel AB. (d) Same as (b) but for MIPAS channel AB.
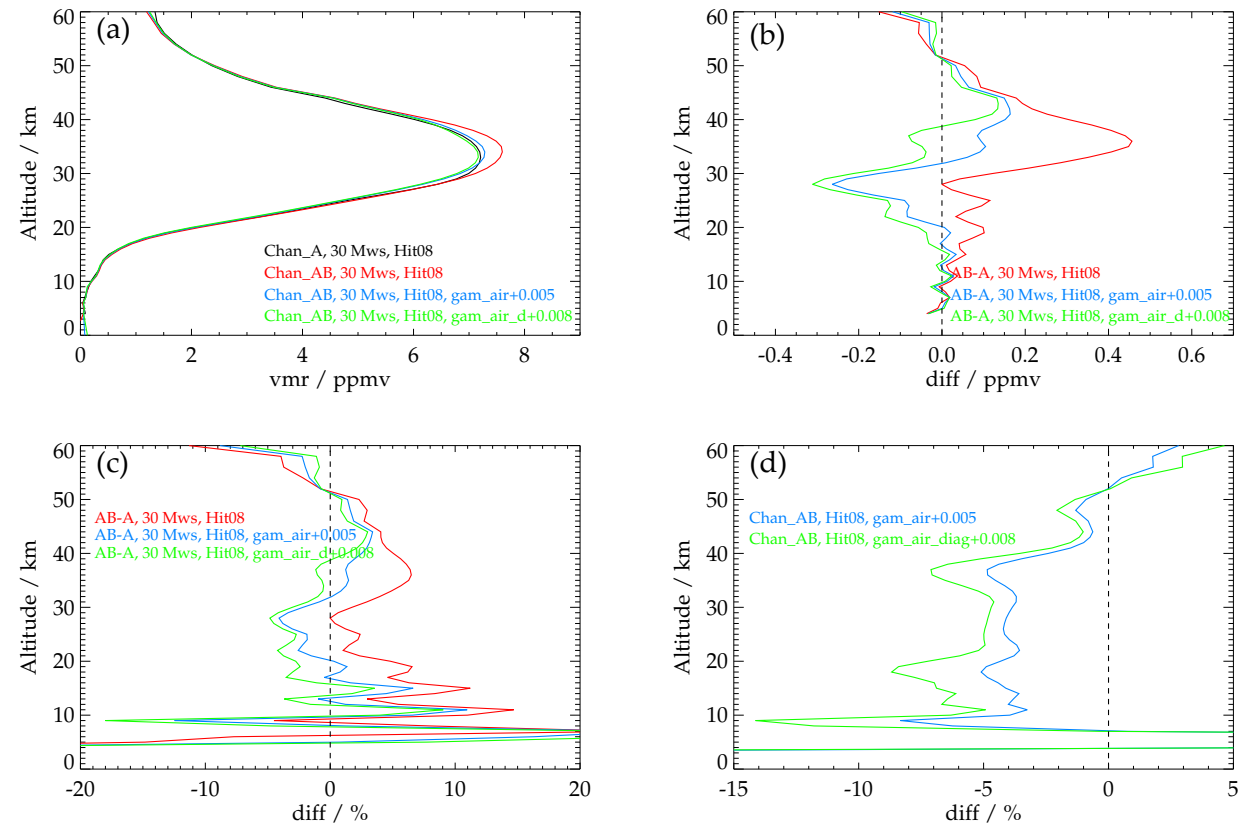

Figure 11. (a) Mean ozone profiles of 59 orbits from 3 January, 1 April, 2 July and 2-3 October 2009, retrieved in MIPAS channels A (black) and AB (red) using the HITRAN-2008 spectroscopy (see Fig. 1). The blue profile results from retrieval in MIPAS channel AB after an increase in the air-broadened half widths by a value of $0.005 \mathrm{~cm}^{-1} \mathrm{~atm}^{-1}$ at $296 \mathrm{~K}$, and the green profile from retrieval after increase in the air-broadened half widths of the strong lines on the main diagonal in Fig. $8 \mathrm{~b}$ by $0.008 \mathrm{~cm}^{-1} \mathrm{~atm}^{-1}$ at $296 \mathrm{~K}$. (b) Absolute and (c) relative differences between retrievals in channels $\mathrm{AB}$ and $\mathrm{A}$. (d) Differences between channel AB retrievals with increased air-broadened half widths and channel AB retrievals using the unmodified HITRAN-2008 spectroscopy. 

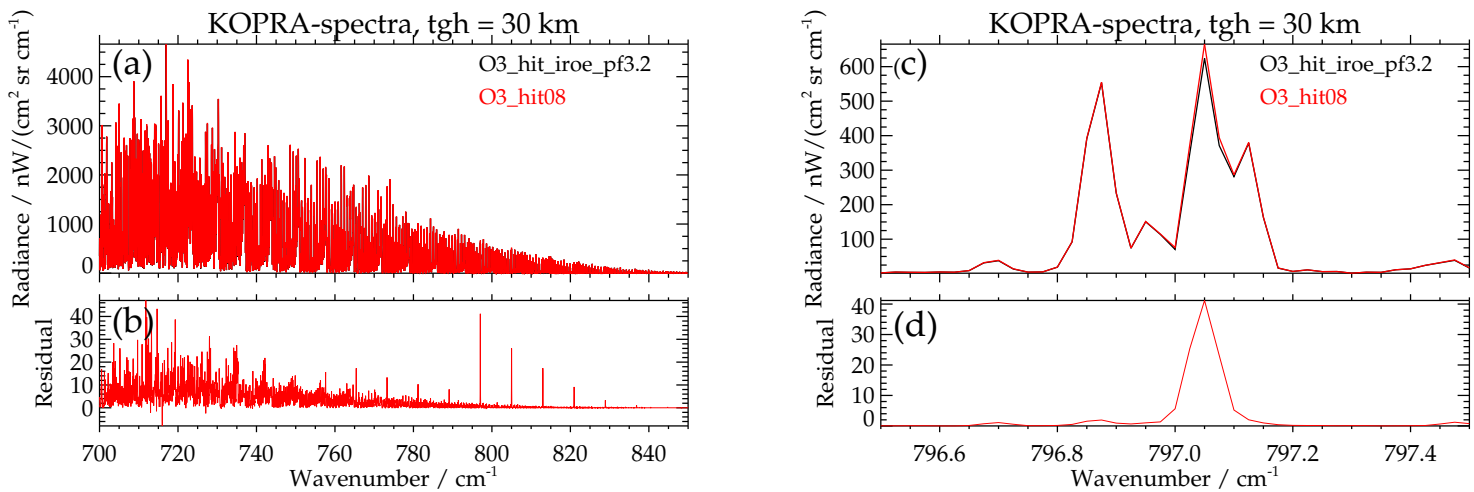

Figure 12. (a) Modelled ozone spectra for a tangent height of $30 \mathrm{~km}$ using the MIPAS-pf3.2 (black) and HITRAN-2008 spectroscopy (red). (b) Difference between the two simulations. (c, d) Same as on the left but for a close-up of the spectral region around $797.0 \mathrm{~cm}^{-1}$.

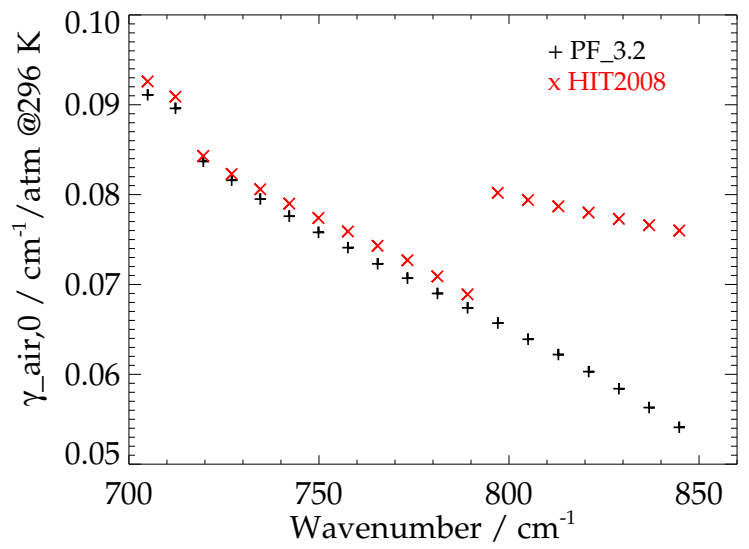

Figure 13. Air-broadened half widths $\gamma_{\text {air, } 0}$ of several ozone lines of the fundamental $v_{2}$ ozone band in the MIPAS-pf3.2 (black) and HITRAN-2008 spectroscopy (red).

by inconsistent $\gamma_{\mathrm{air}, 0}$ values as well. We carried out two additional tests to check whether the differences can be reduced by modification of the air-broadened half widths. In the first test we increased the half widths of the HITRAN2008 ozone lines in the spectral region of MIPAS channel AB by $0.005 \mathrm{~cm}^{-1} \mathrm{~atm}^{-1}$ at $296 \mathrm{~K}(5 \%-7 \%)$. Caused by this change, the deviations in the height range $32-45 \mathrm{~km}$ are considerably reduced compared to the retrieval using the unmodified HITRAN-2008 database, namely to $0.15 \mathrm{ppmv}$ or less (Fig. 11). On the other hand, there are now larger negative deviations of up to $-0.2 \mathrm{ppmv}$ in the height range 18$32 \mathrm{~km}$. In the second test we increased the half widths of the strongest lines on the main diagonal in Fig. 8 (right) by $0.008 \mathrm{~cm}^{-1} \mathrm{~atm}^{-1}$ at $296 \mathrm{~K}$ to obtain a similar distribution like the channel A correlation in Fig. 8 (left). This led to even lower differences between 18 and $32 \mathrm{~km}$ but to somewhat larger negative differences between 18 and $32 \mathrm{~km}$.

As a side aspect, Fig. 11d shows the differences between the channel $\mathrm{AB}$ retrievals with increased air-broadened half widths and the channel $\mathrm{AB}$ retrievals using the unmodified HITRAN-2008 spectroscopy. Since these differences are relatively constant around -4 and $-5 \%$ over the altitude region $10-40 \mathrm{~km}$, they are good estimates of the respective changes in ozone column amounts. Thus, this result shows that, alternatively to the proposed rescaling of line intensities in the $10 \mu \mathrm{m}$ region (see Sect. 1), the bias between ozone column amounts measured in the mid-infrared and UV spectral regions, e.g. shown by Schneider et al. (2008), could probably also be reduced by a change in the air-broadened half widths.

\section{Additional investigations}

To substantiate the possibility of inconsistent $\gamma_{\text {air, } 0}$ values, Fig. 12 shows modelled ozone spectra using the HITRAN2008 and the MIPAS spectroscopy for a tangent altitude of $30 \mathrm{~km}$. In the difference plot (Fig. 12b) a number of conspicuous lines belonging to the fundamental $v_{2}$ band can be identified between 797 and $830 \mathrm{~cm}^{-1}$ (note that these lines are not contained in our set of channel A microwindows). The line intensities of these transitions are identical in both spectroscopic line lists and thus not responsible for the deviations between the model spectra. However, there are substantial differences between the air-broadened half widths (Fig. 13). The half widths of the lines of the MIPAS database continuously decrease between 700 and $850 \mathrm{~cm}^{-1}$. The HITRAN-2008 values are slightly larger, but decrease in a comparable manner up to $\sim 790 \mathrm{~cm}^{-1}$. However, there is a strong increase of more than $0.01 \mathrm{~cm}^{-1} \mathrm{~atm}^{-1}$ at $296 \mathrm{~K}$ at $\sim 797 \mathrm{~cm}^{-1}$, leading to significantly larger values up to $850 \mathrm{~cm}^{-1}$. This jump in $\gamma_{\text {air, } 0}$ is the reason for the stronger ozone lines in the model spectrum using HITRAN-2008 data in Fig. 12. This artefact is still present in later versions up to HITRAN-2016. In addition to the spikes at and above $797.05 \mathrm{~cm}^{-1}$ the difference plot (Fig. 12b) also exhibits somewhat smaller peaks for the $v_{2}$ transitions at lower wave numbers, e.g. at $789.11,781.18,773.29$ and $765.43 \mathrm{~cm}^{-1}$. 
This indicates potential additional spectroscopic inconsistencies below $797 \mathrm{~cm}^{-1}$ in the HITRAN-2008 database.

To further demonstrate the inconsistencies of the spectroscopic parameters of the lines above $790 \mathrm{~cm}^{-1}$ in the HITRAN-2008 data base identified above, broadband ozone retrievals were performed in the wave number range 795 to $825 \mathrm{~cm}^{-1}$ for MIPAS orbits $39680-39693$. In addition to ozone, peroxyacetyl nitrate (PAN), $\mathrm{CCl}_{4}, \mathrm{ClONO}_{2}$ and HCFC-22 were jointly fitted. The spectral signatures of additional gases were modelled by the use of pre-fitted or climatological profiles. Figure 14 shows the residuals between mean modelled and measured spectra using the HITRAN2008 and the MIPAS pf3.2 ozone spectroscopy for the latitude region $30^{\circ} \mathrm{S}-30^{\circ} \mathrm{N}$ and tangent heights covering the altitude region of $\sim 14-44 \mathrm{~km}$. For the major part of the spectral region the residuals resulting from both spectroscopies are very similar, leading to a nearly complete coverage of the HITRAN-2008-residual. The large "blue" residuals are mainly caused by inadequately modelled $\mathrm{CO}_{2}$ and $\mathrm{H}_{2} \mathrm{O}$ lines. However, for tangent heights of 14, 20 and $30 \mathrm{~km}$, use of the HITRAN-2008 spectroscopy leads to large residuals (red) at the positions of the lines with higher $\gamma_{\text {air,0 }}$ values (797.05, 805.02 and $812.99 \mathrm{~cm}^{-1}$ ). The spectroscopic parameters of these lines are not consistent with those of all the other ozone lines in the broad spectral range used for retrieval, and thus these lines cannot be fitted properly. At $44 \mathrm{~km}$ these residuals have disappeared, showing that the influence of different air-broadened half widths becomes negligible at this altitude.

At first glance it seems a bit strange that increased airbroadened half widths lead to modelled ozone lines which exhibit stronger peak radiances (Fig. 12). To investigate this behaviour in more detail, model calculations with KOPRA were made for an isolated ozone line. For a homogeneous, optical thin atmosphere larger $\gamma_{\text {air, } 0}$ values lead to lower radiances in the line centre and to higher radiances at the line wings for both the monochromatic line and after folding with the apodized internal line shape (AILS) (not shown). However, for a limb observation through the Earth's atmosphere the result becomes different. For a tangent altitude of $30 \mathrm{~km}$ a larger air-broadened half width also leads to a larger half width and lower peak radiance of the modelled monochromatic line (Fig. 15a), but there is a significantly larger growth in radiance at the wings compared to the decline in the line centre (Fig. 15b). In this case, convolution with the AILS as performed in MIPAS retrievals indeed leads to a higher peak radiance (Fig. 15c, d).

\section{Summary and conclusions}

We have reassessed the bias in the altitude range $30-45 \mathrm{~km}$ between ozone retrievals using microwindows in MIPAS channels A (685-970 $\left.\mathrm{cm}^{-1}\right)$ and AB $\left(1020-1170 \mathrm{~cm}^{-1}\right)$. We found that the bias, originally detected in retrievals using V3O-spectra of the MIPAS high spectral resolution measure- ment period and the MIPAS spectroscopy, also occurs for retrievals using later versions of level-1B spectra (V5R, V7R) of the MIPAS reduced spectral resolution mode. The effect amounts to $8 \%$ at the altitude of $36 \mathrm{~km}$. Forward-modelling issues as reason for the problem could be excluded by the fact that similar differences also resulted from retrievals using the processor at the University of Bologna. Spectral calibration or line-of-sight issues could largely be excluded, because retrievals from a different experiment (MIPAS-balloon spectra) also resulted in similar differences. Nevertheless, a number of forward-modelling, instrumental and calibration issues were examined but did not lead to an explanation. The most plausible explanation left was inconsistencies in spectroscopic data.

Therefore additional retrievals were performed using several editions of the HITRAN database, which, however, led to rather similar, even somewhat larger channel AB-A differences in retrieved ozone than those resulting from application of the MIPAS line list. One exception is the HITRAN1996 edition, which causes positive differences above, but negative differences below $32 \mathrm{~km}$. Since the channel AB-A bias did not disappear by application of any of the HITRAN databases, we carried out another retrieval test with a different spectroscopic database, namely the GEISA-2015 compilation. For measurements in MIPAS channel AB, the resulting ozone profiles are rather similar to those based on the HITRAN-2008 spectroscopy. However, for channel A retrievals the stratospheric ozone VMRs based on GEISA2015 are up to 0.8 ppmv or about $10 \%$ larger than those based on HITRAN-2008 and even larger than the VMRs retrieved in channel AB. According to the results of the validation study by Laeng et al. (2014), these VMRs are obviously too high. We showed that the differences in channel A retrievals are not caused by inconsistent line intensities, but by $\sim 13 \%$ lower air-broadened half widths of the strongest ozone lines in the channel A microwindows in the GEISA-2015 database. Since the relative differences between band intensities in the spectral ranges used in MIPAS channels $\mathrm{A}$ and $\mathrm{AB}$ are assumed to be considerably lower than the observed bias of $6 \%-8 \%$, we suggest that a major part of the channel $\mathrm{AB}-\mathrm{A}$ differences might be caused by inconsistencies in air-broadened half widths in the individual line databases as well. To substantiate this assumption we identified several ozone lines in the HITRAN-2008 database, which exhibit too-large air-broadened half widths. The bias between channel A and AB can partly be reduced by increasing the air-broadened half widths of the lines in channel AB. In summary, the air-broadened half widths of ozone lines in the spectral regions of MIPAS channel A as well as of channel AB (i.e. the regions of the $v_{2}, v_{1}$ and $v_{3}$ fundamental bands) should be reassessed both for the GEISA and for the HITRAN databases. This is especially necessary for the GEISA- $v_{2}$ lines in MIPAS channel A.

According to the investigations with our microwindow data sets, for the time being, the best choice of an ozone line 

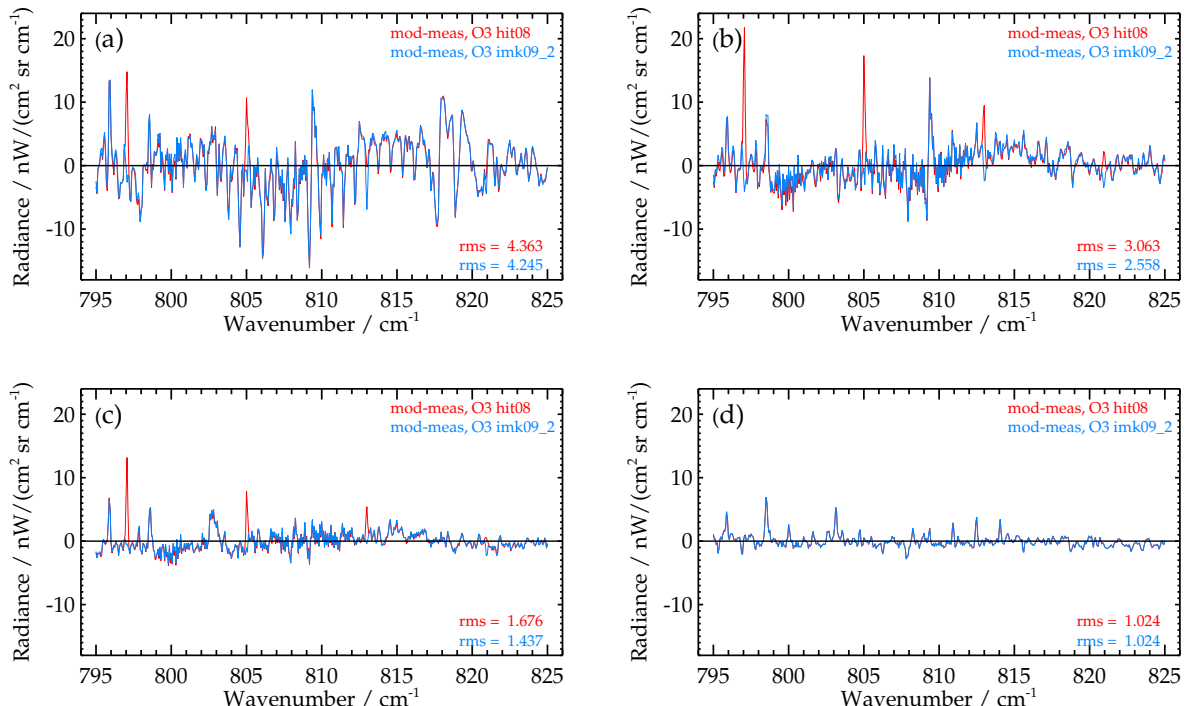

Figure 14. Residua between mean modelled and measured spectra using the HITRAN-2008 (red) and the MIPAS-pf3.2 ozone spectroscopy (blue) for tangent heights of (a) $\sim 14 \mathrm{~km},(\mathbf{b}) \sim 20 \mathrm{~km}$, (c) $\sim 30 \mathrm{~km}$ and (d) $\sim 44 \mathrm{~km}$. Averaging over $302(14 \mathrm{~km})$ and $442 \mathrm{spectra}$ (higher altitudes) of 14 consecutive orbits (39680-39693) for the latitude range $30^{\circ} \mathrm{S}-30^{\circ} \mathrm{N}$. The large red residua of the ozone lines at 797,805 and $813 \mathrm{~cm}^{-1}$ are caused by inappropriate air-broadening coefficients in the HITRAN-2008 spectroscopy.
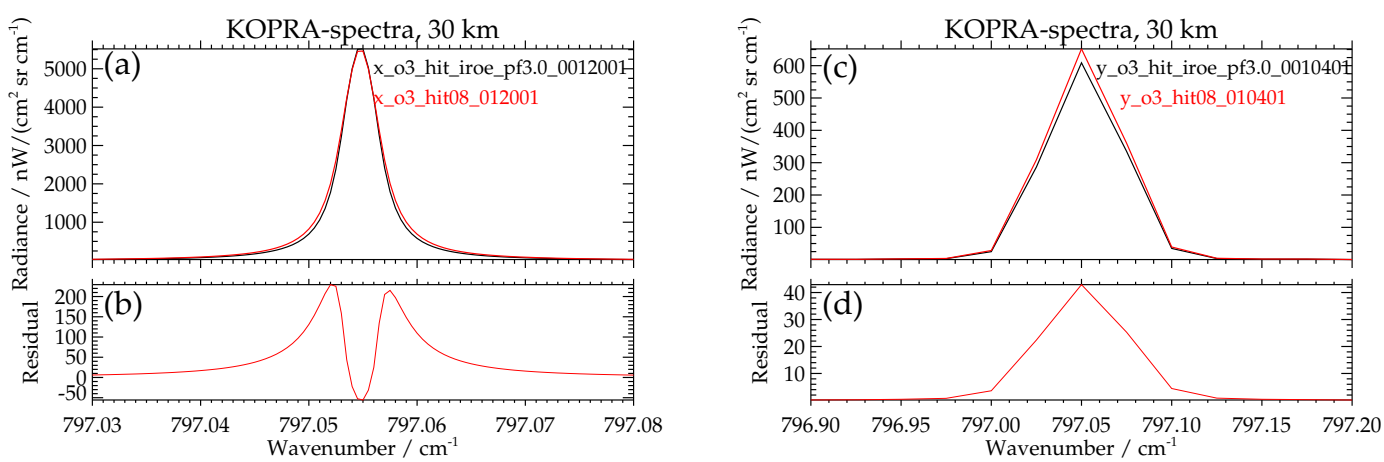

Figure 15. (a) Modelled spectral signature of the ozone line at $797.05 \mathrm{~cm}^{-1}$ for a limb observation with a tangent height of $30 \mathrm{~km}$ using the MIPAS-pf3.2 (black) and the HITRAN-2008 spectroscopy (larger $\gamma_{\text {air,0) }}$ (red), monochromatic lines. (b) Corresponding residual. (c, d) Same as on the left but lines convolved with the apodized instrumental line shape.

data compilation for evaluation of MIPAS measurements is the MIPAS spectroscopy (Flaud et al., 2003b), because, on the one hand, the channel $\mathrm{AB}-\mathrm{A}$ differences are somewhat smaller than those resulting from the HITRAN databases, and on the other hand, it does not contain the inconsistency in some air-broadened half widths identified in HITRAN2008, which were also transferred to later HITRAN versions. However, as far as ozone is concerned we recommend using version pf 3.2 of the MIPAS spectroscopy and not the latest update pf4.45 (Flaud, et al., 2015, http://atmos.difa.unibo.it/ spectdb/, last access: 2 August 2018), because the ozone data set in this compilation is identical to HITRAN-2008.
Data availability. The corresponding retrieval set-ups and the resulting channel $\mathrm{A}$ and $\mathrm{AB}$ profiles can be obtained on request from the main author.

Supplement. The supplement related to this article is available online at: https://doi.org/10.5194/amt-11-4707-2018-supplement.

Author contributions. NG performed most of the retrievals, the comparisons of spectroscopic parameters, the preparation of most of the figures and wrote the first draft of the manuscript. TvC and GPS gave valuable contributions to the formulation of the manuscript. MK performed additional test retrievals, helped in figure preparations and contributed to the text. AL contributed to the text. BMD provided the Bologna retrievals. GW made the MIPAS- 
balloon retrievals and contributed to the text. JO gave helpful comments and references to the state-of-the-art of ozone interband inconsistencies.

Competing interests. The authors declare that they have no conflict of interest.

Acknowledgements. The authors would like to thank the European Space Agency for providing access to MIPAS level-1 data. The project underlying this paper was funded by the German Federal Ministry for Economic Affairs and Energy under project number 50EE1547 (SEREMISA). Further, this study was partly supported by the ESA CCI-O3 project. Meteorological analysis data were provided by the European Centre for Medium-Range Weather Forecasts. We acknowledge support by the Deutsche Forschungsgemeinschaft and the Open Access Publishing Fund of the Karlsruhe Institute of Technology. Further, we thank Frank Hase for helpful discussions.

The article processing charges for this open-access

publication were covered by a Research

Centre of the Helmholtz Association.

Edited by: Andrew Sayer

Reviewed by: two anonymous referees

\section{References}

Carlotti, M., Brizzi, G., Papandrea, E., Prevedelli, M., Ridolfi, M., Dinelli, B. M., and Magnani, L.: GMTR: Two-dimensional geofit multitarget retrieval model for Michelson Interferometer for Passive Atmospheric Sounding/Environmental Satellite observations, Appl. Opt., 45, 716-727, 2006.

Fischer, H., Birk, M., Blom, C., Carli, B., Carlotti, M., von Clarmann, T., Delbouille, L., Dudhia, A., Ehhalt, D., Endemann, M., Flaud, J. M., Gessner, R., Kleinert, A., Koopman, R., Langen, J., López-Puertas, M., Mosner, P., Nett, H., Oelhaf, H., Perron, G., Remedios, J., Ridolfi, M., Stiller, G., and Zander, R.: MIPAS: an instrument for atmospheric and climate research, Atmos. Chem. Phys., 8, 2151-2188, https://doi.org/10.5194/acp-8-21512008, 2008.

Flaud J.-M. and Bacis, R.: The ozone molecule: infrared and microwave spectroscopy, Spectrochim. Acta, 54, 3-16, 1998.

Flaud, J.-M., Wagner, G., Birk, M., Camy-Peyret, C., Claveau, C., De Backer-Barilly, M. R., Barbe, A., and Piccolo, C.: Ozone absorption around $10 \mu \mathrm{m}$, J. Geophys. Res., 108, 4269, https://doi.org/10.1029/2002JD002755, 2003a.

Flaud, J.-M., Piccolo, C., Carli, B., Perrin, A., Coudert, L. H., Teffo, J. L., and Brown, L. R.: Molecular line parameters for the MIPAS (Michelson Interferometer for Passive Atmospheric Sounding) experiment, Atmos. Ocean. Opt., 16, 172-182, $2003 \mathrm{~b}$.

Friedl-Vallon, F., Maucher, G., Seefeldner, M., Trieschmann, O., Kleinert, A., Lengel, A., Keim, C., Oelhaf, H., and Fischer, H.: Design and characterization of the balloonborne Michelson Interferometer for Passive Atmospheric
Sounding (MIPAS-B2), Appl. Opt., 43, 3335-3355, https://doi.org/10.1364/AO.43.003335, 2004.

Glatthor, N., von Clarmann, T., Fischer, H., Funke, B., GilLópez, S., Grabowski, U., Höpfner, M., Kellmann, S., Linden, A., López-Puertas, M., Mengistu Tsidu, G., Milz, M., Steck, T., Stiller, G. P., and Wang, D.-Y.: Retrieval of stratospheric ozone profiles from MIPAS/ENVISAT limb emission spectra: a sensitivity study, Atmos. Chem. Phys., 6, 2767-2781, https://doi.org/10.5194/acp-6-2767-2006, 2006.

Gordon, I. E., Rothman, L. S., Hill, C., Kochanov, R. V., Tan, Y., Bernath, P. F., Birk, M., Boudon, V. Campargue, A., Chance, K. V., Drouin, B. J., Flaud, J.-M., Gamache, R. R., Hodges, J. T., Jacquemart, D., Perevalov, V. I., Perrin, A., Shine, K. P., Smith, M. A. H., Tennyson, J., Toon, G. C., Tran, H., Tyuterev, V. G., Barbe, A., Császár, A. G., Devi, V. M., Furtenbacher, T., Harrison, J. J., Hartmann, J.-M., Jolly, A. Johnson, T. J., Karman, T., Kleiner, I., Kyuberis, A. A., Loos, J., Lyulin, O. M., Massie, S. T., Mikhailenko, S. N., Moazzen-Ahmadi, N., Müller, H. S. P., Naumenko, O. V., Nikitin, A. V., Polyansky, O. L., Rey, M., Rotger, M., Sharpe, S. W., Sung, K., Starikova, E., Tashkun, S. A., Vander Auwera, J., Wagner, G., Wilzewski, J., Wcisło, P., Yu, S., and Zak, E. J.: The HITRAN2016 molecular spectroscopic database, J. Quant. Spectrosc. Ra., 203, 3-69, https://doi.org/10.1016/j.jqsrt.2017.06.038, 2017.

Gratien, A., Picquet-Varrault, B., Orphal, J., Doussin, J.-F., and Flaud, J.-M.: New Laboratory Intercomparison of the Ozone Absorption Coefficients in the Mid-infrared $(10 \mu \mathrm{m})$ and Ultraviolet (300-350 nm) Spectral Regions, J. Phys. Chem. A, 114, 1004510048, 2010.

Guinet, M., Mondelain, D., Janssen, C., and Camy-Peyret, C.: Laser spectroscopic study of ozone in the 100-000 band for the SWIFT instrument, J. Quant. Spectrosc. Ra., 111, 961-972, https://doi.org/10.1016/j.jqsrt.2010.01.011, 2010.

Höpfner, M., von Clarmann, T., Fischer, H., Glatthor, N., Grabowski, U., Kellmann, S., Kiefer, M., Linden, A., Mengistu Tsidu, G., Milz, M., Steck, T., Stiller, G. P., Wang, D.-Y., and Funke, B.: First spaceborne observations of Antarctic stratospheric $\mathrm{ClONO}_{2}$ recovery: Austral spring 2002, J. Geophys. Res., 109, D11308, https://doi.org/10.1029/2004JD004609, 2004.

Jacquinet-Husson, N., Scott, N. A., Chédin, A., Crépeau, L., Armante, R., Capelle, V., Orphal, J., Coustenis, A., Boonne, C., Poulet-Crovisier, N., Barbe, A., Birk, M., Brown, L. R., CamyPeyret, C., Claveau, C., Chance, K., Christidis, N., Clerbaux, C., Coheur, P. F., Danah, V., Daumont, L., De Backer-Barilly, M. R., Di Lonardo, G., Flaud, J.-M., Goldmann, A., Hamdouni, A., Hess, M., Hurley, M. D., Jacquemart, D., Kleiner, I., Köpke, P., Mandin, J. Y., Massier, S., Mikhailenko, S., Nemtchinov, V., Nikitin, A., Newnham, D., Perrin, A., Perevalov, V. I., Pinnock, S., Régalia-Jarlot, L., Rinsland, C. P., Rublev, A., Schreier, F., Schult, L., Smith, K. M., Tashkun, S. A., Teffo, J. L., Toth, R. A., Tyuterev, Vl. G., Vander Auwera, J., Varanasi, P., and Wagner, G.: The GEISA spectroscopic database: Current and future archive for Earth and planetary atmosphere studies, J. Quant. Spectrosc. Ra., 109, 1043-1059, https://doi.org/10.1016/j.jqsrt.2007.12.015, 2008.

Jacquinet-Husson, N., Armante, R., Scott, N. A., Chédin, A., Crépeau, L., Boutammine, C., Bouhdaoui, A., Crevoisier, C., Capelle, V., Boonne, C., Poulet-Crovisier, N., Barbe, A., Ben- 
ner, C. D., Boudon, V., Brown, L. R., Buldyreva, J., Campargue, A., Coudert, L. H., Devi, V. M., Down, M. J., Drouin, B. J., Fayt, A., Fittschen, C., Flaud, J.-M., Gamache, R. R., Harrison, J. J., Hill, C., Hodnebrog, Ø., Hu, S.-M., Jacquemart, D., Jolly, A., Jiménez, E., Lavrentieva, N. N., Liu, A.-W., Lodi, L., Lyulin, O. M., Massie, S. T., Mikhailenko, S., Müller, H. S. P., Naumenko, O. V., Nikitin, A., Nielsen, C. J., Orphal, J., Perevalov, V. I., Perrin, A., Polovtseva, E., Predoi-Cross, A., Rotger, M., Ruth, A. A., Yu, S. S., Sung, K., Tashkun, S. A., Tennyson, J., Tyuterev, Vl. G., Vander Auwera, J., Voronin, B. A., and Makie, A.: The 2015 edition of the GEISA spectroscopic database, J. Mol. Spectrosc., 327, 31-72, https://doi.org/10.1016/j.jms.2016.06.007, 2016.

Laeng, A., Grabowski, U., von Clarmann, T., Stiller, G., Glatthor, N., Höpfner, M., Kellmann, S., Kiefer, M., Linden, A., Lossow, S., Sofieva, V., Petropavlovskikh, I., Hubert, D., Bathgate, T., Bernath, P., Boone, C. D., Clerbaux, C., Coheur, P., Damadeo, R., Degenstein, D., Frith, S., Froidevaux, L., Gille, J., Hoppel, K., McHugh, M., Kasai, Y., Lumpe, J., Rahpoe, N., Toon, G., Sano, T., Suzuki, M., Tamminen, J., Urban, J., Walker, K., Weber, M., and Zawodny, J.: Validation of MIPAS IMK/IAA V5R_O3_224 ozone profiles, Atmos. Meas. Tech., 7, 39713987, https://doi.org/10.5194/amt-7-3971-2014, 2014.

Nett, H., Perron, G., Sanchez, M., Burgess, A., and Mossner, P.: MIPAS inflight calibration and processor validation, in: ENVISAT Calibration Review - Proc. of the European Workshop, 9-13 September 2002, ESTEC, Noordwijk, the Netherlands, CD-ROM, vol. SP-520, edited by: Sawaya-Lacoste, H., ESA Publications Division, ESTEC, Postbus 299, 2200 AG Noordwijk, the Netherlands, 2002.

Orphal, J., Staehelin, J., Tamminen, J., Braathen, G., De Backer, M.-R., Bais, A., Balis, D., Barbe, A., Bhartia, P. K., Birk, M., Burkholder, J. B., Chance, K., von Clarmann, T., Cox, A., Degenstein, D., Evans, R., Flaud, J.-M., Flittner, D., GodinBeekmann, S., Gorshelev, V., Gratien, A., Hare, E., Janssen, C., Kyrölä, E., McElroy, T., McPeters, R., Pastel, M., Petersen, M., Petropavlovskikh, I., Picquet-Varrault, B., Pitts, M., Labow, G., Rotger-Languereau, M., Leblanc, T., Lerot, C., Liu, X., Moussay, P., Redondas, A., Van Roozendael, M., Sander, S. P., Schneider, M., Serdyuchenko, A., Veefkind, P., Viallon, J., Viatte, C., Wagner, G., Weber, M., Wielgosz, R. I., and Zehner, C.: Absorption cross-sections of ozone in the ultraviolet and visible spectral regions: Status report 2015, J. Mol. Spectrosc., 327, 105-121, https://doi.org/10.1016/j.jms.2016.07.007, 2016.

Picquet-Varrault, B., Orphal, J., Doussin, J.-F., Carlier, P., and Flaud, J.-M.: Laboratory Intercomparison of the Ozone Absorption Coefficients in the Mid-infrared $(10 \mu \mathrm{m})$ and Ultraviolet (300-350 nm) Spectral Regions, J. Phys. Chem. A, 109, 10081014, 2005.

Remedios, J. J., Leigh, R. J., Waterfall, A. M., Moore, D. P., Sembhi, H., Parkes, I., Greenhough, J., Chipperfield, M. P., and Hauglustaine, D.: MIPAS reference atmospheres and comparisons to V4.61/V4.62 MIPAS level 2 geophysical data sets, Atmos. Chem. Phys. Discuss., 7, 9973-10017, https://doi.org/10.5194/acpd-7-9973-2007, 2007.
Rothman, L. S., Jacquemart, D., Barbe, A., Benner, D. C., Birk, M., Brown, L. R., Carleer, M. R., Chackerian Jr., C., Chance, K., Coudert, L. H., Dana, V., Devi, V. M., Flaud, J.-M., Gamache, R. R., Goldman, A., Hartmann, J.-M., Jucks , K. W., Maki, A. G., Mandin, J.-Y., Massie, S. T., Orphal , J., Perrin, A., Rinsland, C. P., Smith, M. A. H., Tennyson, J., Tolchenov, R. N., Toth, R. A., Vander Auwera, J., Varanasi, P., and Wagner, G.: The HITRAN 2004 molecular spectroscopic database, J. Quant. Spectrosc. Ra., 96, 139-204, https://doi.org/10.1016/j.jqsrt.2004.10.008, 2005.

Rothman, L. S., Gordon, I. E., Barbe, A., Benner, D. C., Bernath, P. F., Birk, M., Boudon, V., Brown, L. R., Campargue, A., Champion, J.-P., Chance, K., Coudert, L. H., Dana, V., Devi, V. M., Fally, S., Flaud, J.-M., Gamache, R. R., Goldman, A., Jacquemart, D., Kleiner, I., Lacome, N., Lafferty, W. J., Mandin, J.-Y., Massie, S. T., Mikhailenko, S. N., Miller, C. E., Moazzen-Ahmadi, N., Naumenko, O. V., Nikitin, A. V., Orphal, J., Perevalov, V. I., Perrin, A., Predoi-Cross, A., Rinsland, C. P., Rotger, M., Šimečková, M., Smith, M. A. H., Sung, K., Tashkun, S. A., Tennyson, J., Toth, R. A., Vandaele, A. C., and Vander Auwera, J.: The HITRAN 2008 molecular spectroscopic database, J. Quant. Spectrosc. Ra., 110, 533-572, https://doi.org/10.1016/j.jqsrt.2009.02.013, 2009.

Schneider, M., Redondas, A., Hase, F., Guirado, C., Blumenstock, T., and Cuevas, E.: Comparison of ground-based Brewer and FTIR total column $\mathrm{O}_{3}$ monitoring techniques, Atmos. Chem. Phys., 8, 5535-5550, https://doi.org/10.5194/acp-8-5535-2008, 2008.

Smith, M. A. H., Devi, V. M., and Benner, D. C.: The quest for ozone intensities in the $9-11 \mu \mathrm{m}$ region: A retrospective, J. Quant. Spectrosc. Ra., 113, 825-828, https://doi.org/10.1016/j.jqsrt.2012.02.027, 2012.

Stiller, G. P. (Ed.): The Karlsruhe Optimized and Precise Radiative transfer Algorithm (KOPRA), Institut für Meteorologie und Klimaforschung, Forschungszentrum Karlsruhe GmbH, 2000.

Tran, H., Rohart, F., Boone, C., Eremenko, M., Hase, F., Bernath, P., and Hartmann, J.-M.: Non-Voigt line-shape effects on retrievals of atmospheric ozone: Collisionally isolated lines, J. Quant. Spectrosc. Ra., 111, 2012-2020, https://doi.org/10.1016/j.jqsrt.2010.04.002, 2010.

von Clarmann, T., Fischer, H., Funke, B., Glatthor, N., Grabowski, U., Höpfner, M., Kellmann, S., Kiefer, M., Linden, A., Mengistu Tsidu, G., Milz, M., Steck, T., Stiller, G. P., Wang, D.-Y., GilLópez, S., and López-Puertas, M.: Retrieval of temperature and tangent altitude pointing from limb emission spectra recorded from space by the Michelson Interferometer for Passive Atmospheric Sounding (MIPAS), J. Geophys. Res., 108, D23, https://doi.org/10.1029/2003JD003602, 2003.

Wagner, G., Birk, M., and Schreier, F.: Spectroscopic database for ozone in the fundamental spectral regions, J. Geophys. Res., 107, 4626, https://doi.org/10.1029/2001JD000818, 2002. 